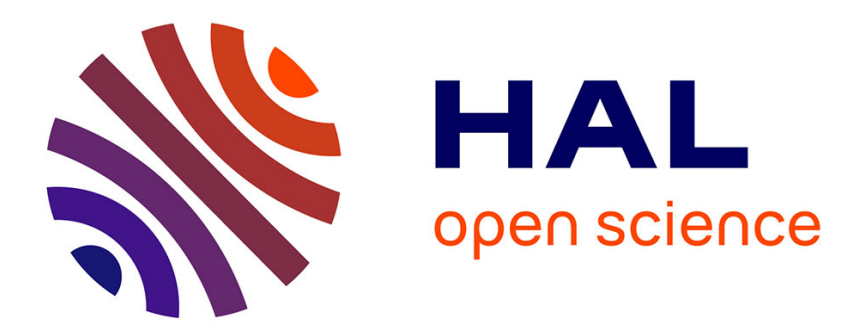

\title{
Revisiting the concept of characteristic compressive strength of concrete
}

Chi-Cong Vu, Olivier Plé, Jérôme Weiss, David Amitrano

\section{To cite this version:}

Chi-Cong Vu, Olivier Plé, Jérôme Weiss, David Amitrano. Revisiting the concept of characteristic compressive strength of concrete. Construction and Building Materials, 2020, 263, pp.120126. 10.1016/j.conbuildmat.2020.120126 . hal-03001586

\section{HAL Id: hal-03001586 https://hal.science/hal-03001586}

Submitted on 19 Nov 2020

HAL is a multi-disciplinary open access archive for the deposit and dissemination of scientific research documents, whether they are published or not. The documents may come from teaching and research institutions in France or abroad, or from public or private research centers.
L'archive ouverte pluridisciplinaire HAL, est destinée au dépôt et à la diffusion de documents scientifiques de niveau recherche, publiés ou non, émanant des établissements d'enseignement et de recherche français ou étrangers, des laboratoires publics ou privés. 


\title{
Revisiting the concept of characteristic compressive strength of concrete
}

\author{
Chi-Cong Vu $u^{\mathrm{a}}$, Olivier Pléb ${ }^{\text {, Jérôme Weiss }}{ }^{\mathrm{c}}$, David Amitrano ${ }^{\mathrm{c}}$ \\ ${ }^{a}$ National University of Civil Engineering (NUCE), 55 Giai Phong, Hanoi, Vietnam \\ ${ }^{b}$ Univ. Savoie Mont Blanc, CNRS, LOCIE, 73000 Chambéry, France \\ ${ }^{c}$ Univ. Grenoble Alpes, CNRS, IRD, IFSTTAR, ISTerre, 38000 Grenoble, France
}

\begin{abstract}
The characteristic compressive strength is one of the most important material property used in structural design and quality control of concrete. Here we show that the estimation of this characteristic strength following classical standard rules (e.g. EN 1992 or ACI-318) is sample size dependent, i.e. is not a characteristic of the material. From an extensive experimental dataset, an analysis of published strength data, and an interpretation of compressive failure as a critical phase transition from an intact to a failed state, we show that the compressive strength of concrete is characterized by a non-vanishing asymptotic mean strength, $\sigma_{\infty}$, but a vanishing associated variability towards very large system sizes. Consequently, the asymptotic strength $\sigma_{\infty}$ can be regarded as the genuine characteristic compressive strength of concrete. Based on this, we propose a new procedure to evaluate this genuine characteristic strength as well as to check the conformity of concrete with strength requirements.
\end{abstract}

Keywords: characteristic compressive strength, size effect, finite-size scaling, concrete, strength variability

\section{Introduction}

In civil engineering, concrete is mostly used under compression loading configurations since its compressive strength is much larger than its tensile and/or flexural strengths. Generally, the tensile and flexural strengths of concrete are of the order of respectively $\sim 10 \%$ and $\sim 15 \%$ of the compressive strength [1]. Furthermore, the compressive strength is often considered as a marker of 
the concrete quality because it is directly related to the structure of the hydrated cement paste [2]. For these reasons, the compressive strength is usually used as the basis for taking decisions regarding the strength and serviceability of concrete members and structures [1].

For the purpose of structural design, concrete is classified into several strength classes based on the so-called characteristic compressive strength $\left(f_{c k}\right)$ in most of European standards (e.g. EN 1992 [3] and NF EN 206-1 [4]) or on the specified compressive strength $\left(f_{c}^{\prime}\right)$ in the American standard (ACI-318 [5]). Hereafter, both $f_{c k}$ and $f_{c}^{\prime}$ are referred as the characteristic strength $\left(f_{c k}\right)$. For example, in the standard EN 1992 [3], the concrete strength class ranges from C12/15 to C90/105, meaning that the characteristic strength of cylinders and that of cubic specimens are respectively in a range $12-90 \mathrm{MPa}$ and $15-105 \mathrm{MPa}$. During the design stage, designers must size the dimensions of the concrete members to resist the imposed loads based on some compressive strength classes. These chosen strength grades are then used to define the concrete mix to be used for construction. In the construction stage, the concrete used must be in conformity with the strength requirements previously specified by the designers from the characteristic strength. Therefore, the characteristic strength can be considered as a key property for structural design, concrete mix design and quality control of concrete.

Implicitly assuming a normal distribution for the compressive strength of concrete samples, in agreement with experimental data $[1-3,5]$, the characteristic strength of concrete $\left(f_{c k}\right)$ is calculated from the corresponding mean value $\left(f_{c m}\right)$ and standard deviation $(s)$ as follows:

$$
f_{c k}=f_{c m}-\lambda \cdot s
$$

, where the constant $\lambda$ sets the acceptable percentage of tests that will fail under a stress lower than $f_{c k}$ (e.g. a fractile of 5\% is used in EN 1992 [3]). These two statistical parameters $\left(f_{c m}\right.$ and $\left.s\right)$ are obtained from an adequate number of uniaxial compression tests (e.g. $\geq 30$ tests recommended in ACI-318 [5]), carried out on standard concrete specimens at a minimum age of 28 days. Different standard samples are used in different countries and sometimes even in the same country. For instance, both 150x300-mm (or 6x12-in.) cylinders and 150-mm (or 6-in.) cubes are used as 
standard specimens in the United States [1,5,6] and in most European countries [3], while 160x320$\mathrm{mm}$ (i.e. $200 \mathrm{~cm}^{2}$ of normalized strength surface) or $110 \times 220-\mathrm{mm}$ (i.e. $100 \mathrm{~cm}^{2}$ of normalized strength surface) cylinders are recommended and used in France [4,7]. However, quasibrittle materials in general, and concrete in particular, exhibit a size-dependent behavior on the nominal compressive strength [8]. Precisely, the mean compressive strength $\left(f_{c m}\right.$ in (1)) decreases with increasing specimen size [9-15]. In addition, it has been shown recently that the strength variability of concrete ( $s$ in Eq. (1)) also decrease with increasing sample size $[15,16]$. These size effects on both $f_{c m}$ and $s$ imply, from relation (1), that the so-called characteristic compressive strength $\left(f_{c k}\right)$ will depend on the size of tested concrete samples, an effect generally not taken into account in concrete mix and structural design. Such size dependence implies that $f_{c k}$ is actually not a characteristic of the material.

We proposed recently that the compressive failure of quasibrittle materials can be interpreted as a critical phase transition between an intact and a failed state [16-19]. This interpretation enabled us to derive finite-size scaling laws for the mean compressive strength $\left(f_{c m}\right)$ as well as the standard deviation $(s)$ which are in remarkable agreement with strength data in various materials like rocks, concrete, coal and ice [16]. In [15], from a large number (527) of uniaxial compression tests, conducted on concrete specimens with three different mixtures (mean aggregate size and proportion) and four different sizes, we demonstrated the pertinence of our critical interpretation as well as of the finite-size scaling laws to account for size effects on the compressive strength of concrete. In particular, this experimental study indicated that (i) a very large system $(L \rightarrow+\infty)$ will have a non-vanishing asymptotic strength $\left(f_{c m_{(L \rightarrow+\infty)}} \rightarrow \sigma_{\infty}\right)$ but a vanishing strength variability $\left(s_{(L \rightarrow+\infty)} \rightarrow 0\right)$, and (ii) the pore structure in hardened concrete samples, rather than the concrete mix, plays a key role in controlling the size effects on compressive strength. These results suggest two important points in terms of estimating the characteristic compressive strength of concrete as follows: 
1- In this framework, the asymptotic strength $\left(\sigma_{\infty}\right)$, which is by construction independent of system size, appears as the genuine characteristic compressive strength of concrete;

2- A laboratory concrete specimen can only be considered as a standard specimen if its size is very large compared with the characteristic size of its pore structure.

Following this statistical size effect analysis of the compressive strength of concrete detailed in [15], we revisit here the concept of characteristic strength by taking into account the two points noted above, through a comparison with the classical expressions of characteristic strength proposed in concrete design codes (EN 1992 [3] and ACI-318 [5]).

Section 2 details the experimental program. Section 3 deals with the density and moisture content of our concretes, and their variations with the sample size and microstructure characteristics. The statistical size effects on compressive strength of our concretes are discussed in Section 4, and then compared with experimental data of size effect on concrete strength available in the literature in Section 5. Results and discussion about the characteristic compressive strength, taking into account these statistical size effects, are discussed in Section 6. Finally, some overall conclusions of this study are given in Section 7.

\section{Experimental program}

Here we present an extensive experimental program based on the physical and mechanical characterizations of 539 concrete cylindrical samples of 3 different concrete mixes and 4 different sizes including 527 tested in compression. While the moisture and density data are presented here for the first time, the compressive strength data have been used in [15] to analyze size effects on both the mean strength $\left(f_{c m}\right)$ and the associated variability $(s)$. Here these data are used to reexamine the concept of characteristic strength, whose the classical definition directly relies on $f_{c m}$ and $s$ (see Eq. (1)). This problem is then further discussed from compressive strength data available in the literature (section 5). Our dataset is however unique, as it allows a sound estimation of strength variability, $s$, which is not the case for these previously published data. 


\subsection{Materials and mix proportions}

The cement used in all mixes was CEM I 52.5N type Portland cement, satisfying the standard NF EN 197-1 [20]. In this study, locally available natural sand was used as the fine aggregate, while coarse aggregates were natural gravel. All the aggregates were dry and clean, and their specific properties conform to the NF EN 12620 [21] and NF EN 1097-5 [22] regulations. The size distribution of aggregates was investigated from a sieving analysis, following NF EN 933-1 [23]. The gradation curves of aggregates used in this work are shown in Fig. 1. Ordinary potable water available in the laboratory was used for the mixing and curing of concrete.

Following the French standard NF EN 206-1 [4], the weight method was applied to prepare three different concrete mixtures based on three different aggregate sizes $\left(d_{g}\right)$ (see Fig. 1 and Table 1): sand $(3.15 \mathrm{~mm})$, medium gravel $(16 \mathrm{~mm})$ and coarse gravel $(25 \mathrm{~mm})$. The corresponding abbreviations for identifying each concrete group are: Fine aggregate (F), Medium aggregate (M) and Coarse aggregate (C) (see Fig. 2b). The volume fraction of aggregates for the coarser mixes (M- and C-concretes) was kept constant at $0.7 \mathrm{~m}^{3} / \mathrm{m}^{3}$ of concrete and the finesse modulus of aggregates for the three mixtures are reported in Table 1 . The water-to-cement $(\mathrm{W} / \mathrm{C})$ ratio was set constant for all specimens in each concrete mixture. The details of each mixture proportion for $1 \mathrm{~m}^{3}$ of concrete are summarized in Table 1. While the F-concrete is a normal mortar in accordance with the standard NF-EN 196-1 [24], the M-concrete can be actually considered as a standard concrete $[1,4,21,25]$.

\subsection{Specimen preparation}

In this work, all concrete specimens were cylinders with a fixed height-to-diameter ratio $h / \phi=$ 2 and, for each concrete mixture, the diameter $(\phi)$ ranged as follows: 40, 70, 110 and $160 \mathrm{~mm}$ (see

Fig. 2a). About 45 samples for each sample diameter $(\phi)$ and aggregate size $\left(d_{g}\right)$, for a total of 539 concrete specimens, were produced. Among these, 12 samples were selected for analyzing the 
initial microstructure (see Appendix A) and the 527 remaining samples were used for compression tests (see section 4).

All concrete samples were cast according to the procedure of normal weight concrete described in NF EN 206-1 [4]. During mixing, cement and aggregates were firstly blended in dry conditions, and water was then added in the mixer. Due to the limited capacity of the concrete mixing center, for a given concrete mixture, samples of $110 \mathrm{~mm}$ and $160 \mathrm{~mm}$ diameters were fabricated from different batches. The smaller samples (40 $\mathrm{mm}$ and $70 \mathrm{~mm}$ in diameter) were coming from a single batch, however different from the batches used for larger samples. The different batches can be considered as a source of strength variability for each material, which will be taken into account by our approach. According to the regulation NF EN 12390-2 [26], the concrete mixtures were poured in cylindrical cardboard molds and compacted by an internal vibrator combined with an external vibrating table to improve the consolidation of the samples.

After casting, all concrete specimens were cured initially for 48 hours by covering the molds with a plastic sheet in a moisture room, following the recommendation of the regulation NF EN 12390-2 [26]. After demolding, the specimens were continually cured in a water basin at a temperature of approximately $20^{\circ} \mathrm{C}$ for 2 months.

At the age of 56 days, all the specimens were cut by diamond grinding discs to ensure planar surfaces and prevent flexural stresses when loading applies. After sawing, the concrete specimens were immediately immersed again in the water basin for an additional month and left exposed to atmosphere in the laboratory until the testing day. According to the recommendation of the regulation NF EN 12390-3 [7], loading tests should be performed after a minimum age of 28 days. In this work, all the loading tests were carried out five months after concrete preparation.

\subsection{Testing procedure}

A series of 527 uniaxial compressive tests was carried out under a load control protocol, following the procedure recommended by the regulation NF EN 12390-3 [7]. As the samples were 
very different in size, two load-control uniaxial compression machines (of different stiffness and loading capacity), complying with the standard NF EN 12390-4 [27], were used. Machine A (Fig. 2c) with a capacity of $3000 \mathrm{kN}$ was used for the three larger sample sizes $(70 \times 140-\mathrm{mm} ; 110 \times 220$ $\mathrm{mm}$ and $160 \times 320-\mathrm{mm}$ cylinders). The stiffness of this machine is 2.9 times stiffer than that of the largest samples. For the remaining size (40x80mm-samples), the uniaxial compression tests were conducted with machine B (Fig. 2d). This machine has a capacity of $300 \mathrm{kN}$ and its stiffness is 3.5 times larger than the stiffness of the small samples. Consequently, the compression machines used in this work are stiff enough to perform reliable strength measurements on our samples. In addition, these two machines have also been verified and certified by the French Accreditation Committee (COFRAC), i.e. are suited for standardized tests.

A constant stress rate of $0.5 \mathrm{MPa} / \mathrm{s}$, corresponding to a strain rate ranging from $2.4 \times 10^{-5} / \mathrm{s}$ to $3.2 \times 10^{-5} / \mathrm{s}$ was applied on the concrete samples placed between two steel-hardened platens of the compression machine until the specimen failed. Loads were continuously measured by the load cell positioned at the top platen (see Fig. 2c) and directly transmitted to the data acquisition system. When the load fell below $50 \%$ of the peak load, loading was automatically stopped. While the bottom steel platen was fixed, the top one could rotate. This enables the upper platen to adjust to the geometrical imperfections of the specimens.

During loading, the load $(F)$ and the axial displacement $(\delta)$ were continuously monitored and recorded at a $5 \mathrm{~Hz}$ frequency. The axial displacement of the bottom platen $(\delta)$ was measured by one Linear Variable Differential Transducer (LVDT) attached on the frame of the machine. However, when a concrete specimen is loaded, both the specimen and the machine deform. As a result, the measured displacement $(\delta)$ is larger than the true axial shortening of the specimen $\left(\Delta_{s p}\right)$. By using a calibration test on an Aluminum sample of known elastic modulus, the elastic deformation of the loading frame was determined as a function of the applied load. The associated displacement was then eliminated from the axial displacement $(\delta)$ to obtain $\Delta_{s p}$. 


\section{Density and Moisture content of hardened concrete}

As a multiphase heterogeneous material, the response of concrete to applied stress is a result of complex interactions and is affected by various factors [28]. According to [1], these factors can be classified into four categories: (1) characteristics and proportions of materials, (2) curing conditions, (3) loading parameters, and (4) specimen parameters.

Within each concrete mixture, all the samples were produced from the same mix proportion as well as using the same casting and curing process (section 2.2). As an identical loading protocol was applied for all the tests (section 2.3), we can neglect the influence of the loading parameters on compressive strength. Regarding specimen parameters, this includes the sample size, and geometry, the microstructural characteristics, the density and the moisture state of hardened concrete $[1,29,30]$. As all our cylindrical concrete samples were prepared with a constant of height/diameter ratio $(h / \phi=2)$, the effect of specimen geometry is thus ignored in this study. The effect of sample size on the compressive strength will be discussed in section 4 . The microstructural characteristics of our concretes (including porosity) have been already detailed elsewhere [15]. We characterize in the appendix the pore structure related to air voids, which plays a major role on size effects on strength (see section 6.2). In the section below, we examine the density and moisture state of our hardened concrete samples, which are potentially affected by the curing conditions [1,2]. The influences of sample size and microstructure on these properties are also described.

\subsection{Density}

Before each loading test, the dimensions and the weight of the sample were measured. An average diameter, $\phi$, was computed from six measures (two for each end of sample and two in the middle of the sample length). The average length, $h$, was obtained from three measurements. Following the standard NF EN 12390-7 [31], the apparent density, $\rho$, of the hardened concrete sample is simply given by: 


$$
\rho=\frac{m}{V}
$$

where $m$ is the mass of the concrete sample and $\mathrm{V}$ the apparent volume $\left(V=h \frac{\pi \phi^{2}}{4}\right)$.

Fig. 3a shows the mean density and its standard deviation for all concrete samples. It is observed that: (i) for a given concrete mixture, the mean apparent densities and the associated standard deviations are similar for all sample sizes. In other words, there is no significant sample size effect on density; (ii) there is a clear correlation between the apparent density and the aggregate gradation (F-, M- and C-concretes) (see Fig. 3a and Table 1), with an increasing density when increasing the aggregate size, as expected; and (iii) the apparent densities range from $2180 \mathrm{~kg} / \mathrm{m}^{3}$ to $2400 \mathrm{~kg} / \mathrm{m}^{3}$, i.e. all our concrete samples comply with the definition of normal-weight concrete [1-4]. Point (i) shows that the size effects on strength discussed below in section 4 cannot result from a size effect on density, as this characteristics is size-independent in our samples.

\subsection{Moisture content}

In hardened concrete, water is present in various states: (i) chemically bounded water within the hydration products, (ii) adsorbed or physically bounded water in gel pores (gel water), and (iii) free water in capillary pores (capillary water) [32]. These different types of water content control the moisture state inside hardened concrete samples and have a considerable effect on the mechanical properties of concrete $[1,2,33]$. In general, the moisture content, which depends on the microstructural characteristics of the material and environmental conditions such as temperature, relative humidity, and air velocity [1], is used to quantitatively characterize the moisture state of concrete.

In this study, the moisture content, $w_{c}$, of the concrete samples was investigated from the following procedure:

1- Right after loading, 10 deformed concrete samples were collected for each sample size and each concrete mixture, and weighted. This weight is noted $m_{1}$; 
2- The deformed concrete samples were kept in a drying oven at $(105 \pm 5)^{\circ} \mathrm{C}$ for a minimum duration of 3 days, according to the regulation NF EN 12390-7 [31]. After this 3-days period, the mass of each dried specimens was measured every 2 hours. When no significant change of the mass was detected over three consecutive measurements, the sample was considered as totally dry and its weight called $m_{2}$; This procedure was done on samples collected after loading, as the moisture content (and so, in particular, such drying procedure) is known to play a significant role on strength.

3- The moisture content of the hardened concrete sample is defined as the mass ratio of water to solid phases in the sample [34], : $w_{c}=\frac{\left(m_{1}-m_{2}\right)}{m_{2}} \times 100 \%$

The mean value and standard deviation of moisture contents for all concrete samples are displayed in Fig. 3b. For a given concrete group, no significant sample size dependence can be observed. In contrast with the density (see Fig. 3a), the largest moistures are observed for the Fconcrete (see Fig. 3b and Table 1). The moisture content is generally affected by the environmental humidity, the cement content and the porosity of the hardened cement paste [1]. In our case, all loading tests were performed on the concrete samples during a short period (an average of 50 loading tests per day). Hence, the environmental conditions can be considered similar for all samples of each concrete group. The F-concrete was prepared with the largest water to cement ratio in the mix (see Table 1). This is the main reason to explain why the F-concrete samples show the highest moisture content.

Compressive strength is known to increase with decreasing moisture in hardened concrete $[2,35]$. However, owing to the low moisture contents $(<5.5 \%)$ observed in our concrete samples (see Table 1), this factor is not expecting to play a significant role on strength in this study [2,33]. In addition, the size-independence of density and moisture content demonstrates that at the time of loading tests, all concrete samples of a given concrete mixture were in a stable moisture state after a long period of curing (5 months). In other words, this enables us to conclude that all loading tests for a given concrete mixture were performed under similar initial conditions. Consequently, the size 
effects on strength discussed below in section 4 must result from some other reasons, and cannot be affected by the density or the moisture content of our samples.

\section{Size effects on compressive strength}

The compressive strength of concrete $\left(\sigma_{f}\right)$ is defined as the maximum stress that the concrete sample can withstand $[1,6,7]$, hence is calculated by dividing the maximum load, $F_{\text {max }}$, carried by the concrete specimen during the test by the average cross-sectional area $\left(\sigma_{f}=4 F_{\max } / \pi \phi^{2}\right)$. Fig. 4 shows the histograms and the corresponding fits to a normal distribution for the compressive strength of our concrete samples. Low values of both the skewness and the kurtosis of the distributions (see Table 2) demonstrate that the compressive strength of our concretes is distributed according to Gaussian statistics. For each individual distribution (fixed sample size and concrete mixture), we also performed Shapiro-Wilk tests with $\alpha=0.01$ and found that the assumption of Gaussian statistics was never rejected.

For a specific concrete mixture and each sample size, the mean value and the standard deviation of the compressive strength were calculated from about 44 tested samples. These values are summarized in Table 2. We observe that both the mean compressive strength, $\left\langle\sigma_{f}\right\rangle$, and the associated variability, $\delta\left(\sigma_{f}\right)$, decrease with increasing sample diameter $(\phi)$ (see Fig. 4) and increasing aggregate size. This is the signature of the size effects on strength mentioned in the introduction.

An energetic, deterministic approach has been proposed to explain size effects on strength in quasi-brittle materials like concrete $[8,36]$. It is related to stress redistribution and associated energy release within a fracture process zone (FPZ), before macroscopic failure. In this framework, size effects on strength ensue when the FPZ becomes non-negligible compared with the structure size. By construction, such a deterministic approach cannot deal with statistical properties such as strength variability, or the probability of failure under a given stress, while these concepts are 
essential in the definition of the characteristic strength (see Eq. (1)). The statistical approach proposed here is fundamentally different. For a more detailed comparison between them, see [15].

The simplest statistical theory of failure is based on the weakest-link hypothesis [37,38], which assumes that microfracturing and damage events do not interact during the rupture process. Recently, we have demonstrated the inadequacy of this assumption [15], hence the inability of the weakest-link theory to describe these external size effects on the compressive failure and strength of heterogeneous materials such as rocks, concrete, etc. Instead, this failure process can be interpreted as a critical phase transition from an intact to a failed state [16]. This is based on an analogy with a generic physical framework for such a critical transition, the so-called depinning transition of an elastic interface moving against a field of obstacles (e.g. $[39,40])$. In the case of concrete, the critical nature of compressive failure was investigated and confirmed from an acoustic emission (AE) survey of damage and microfracturing [19].

In this framework, finite-size effects on strength arise when the correlation length between microfracturing events, which grows during loading, starts interacting with the (finite) sample size as approaching failure. This gives rise to the finite-size scaling laws for the mean value of the compressive strength, $\left\langle\sigma_{f}\right\rangle$, and its standard deviation, $\delta\left(\sigma_{f}\right)$ as follows [16,41]:

$$
\begin{gathered}
\left\langle\sigma_{f}\right\rangle=\sigma_{\infty} \times\left(\frac{L}{L_{m}}\right)^{-1 / v_{F S}}+\sigma_{\infty} \\
\delta\left(\sigma_{f}\right)=\sigma_{\infty} \times\left(\frac{L}{L_{\delta}}\right)^{-1 / v_{F S}}
\end{gathered}
$$

where $v_{F S}$ is the finite-size exponent. The mean-field (material-independent) prediction [39] for this exponent is $v_{F S}=1$. The length scales $L_{m}$ and $L_{\delta}$ are material constants, which are related to the characteristics of the microstructural disorder $[15,16]$. In this context, $\sigma_{\infty}$ is a non-vanishing asymptotic strength for a system of infinite size $(L \rightarrow+\infty)$. Eq. (3) resembles the scaling laws for the mean strength proposed by Bazant $[8,12]$ and Carpinteri [42]. However, it is noteworthy that, in the case of the Bazant's approach, the exponent is a free (empirical) parameter extracted by fitting 
the experimental data (see reviews in $[8,11,43]$ ), while our physical approach gives a theoretical prediction for $v_{F S}$. The approach of Bazant is based on a "deterministic" energetic size effect and that of Carpinteri is based on geometrical arguments of a fracture surface at the ultimate load, while our approach, based on a statistical physics framework (the critical depinning transition), is fully different. It is noteworthy that both previous approaches, by construction, do not give any prediction for the size effects on the associated strength variability, while our approach does (see Eq. (4)). The comparison of our approach with these two previous works was further detailed in a recent paper [15].

A remarkable agreement between Eq. (3) and numerous published data on the mean compressive strength of various materials such as rocks, ice, coal, and concrete, argued for this critical interpretation of compressive failure of heterogeneous materials [16]. In order to describe the size effects on the compressive strength for our concretes, this critical interpretation was also applied in [15]. Once again, a full agreement between the finite-size scaling predictions (Eq. (3) and Eq. (4)) and the compressive strength data was achieved, regardless of the concrete mixture. For each concrete mixture, the asymptotic strength $\sigma_{\infty}$ and the length scales $L_{m, \delta}$ were extracted from the best fits of the scaling on the mean compressive strength $\left\langle\sigma_{f}\right\rangle$ (Eq. (3)) and the standard deviation $\delta\left(\sigma_{f}\right)$ (Eq. (4)), using $v_{F S}=1$ (see [15] for more details). The values of $\sigma_{\infty}$ and of the length scales $L_{m, \delta}$ for our three concrete mixtures are recalled in Table 3. While the length scales $L_{m, \delta}$ strongly vary the concrete mix, the asymptotic strength appears almost independent of the material. In [15], we also reported that the pore structure of the material, rather than the aggregate content, plays a significant role on size effects on the compressive strength of concrete, i.e. the length scales $L_{m, \delta}$ are linked to the characteristics of the pore structure in hardened concrete samples.

In [19], from a campaign of acoustic emission (AE) measurements carried out on our concrete samples during loading (30 tests), the critical nature of compressive failure process was analyzed and confirmed. In particular, this AE analysis gave an experimental value of $v_{F S}=1.1 \pm 0.2$, very 
close to the theoretical value. Consequently, using $v_{F S}=1$, the values of $L_{m}$ reported in Table 3 , and taking $L=\phi$ in Eq. (3), we obtain a remarkable fit of the mean strength scaling (Eq. (3)) for all the concrete samples (see Fig. 5a). A material-independent value of $\sigma_{\infty}=36.9 \mathrm{MPa}$ is obtained from the linear fit on a $\left[\left\langle\sigma_{f}\right\rangle v s .\left(\phi / L_{m}\right)^{-1 / v_{F S}}\right]$ plot (see the inset graph of Fig. 5a). Taking this asymptotic strength value $\sigma_{\infty}$ as well as the values of $L_{\delta}$ reported in Table 3 , we also obtain an excellent agreement between the scaling prediction for the standard deviation (Eq. (4)) and our experimental data (all sample sizes and all concrete mixtures) (see Fig. 5b). This last point shows that our framework adequately takes into account various sources of strength variability, including the internal microstructure, moisture content variability (see section 3.2), as well as the effect of different batches (see section 2.2).

Fig. 5 reveals that, when a structure is of size $L$ much larger than its microstructural disorder related scale $L_{m}$, (i) the mean compressive strength $\left\langle\sigma_{f}\right\rangle$ is not affected by either the concrete mix or the pore structure; (ii) the mean strength $\left\langle\sigma_{f}\right\rangle$ is close to the asymptotic strength $\sigma_{\infty}$, while the associated variability $\delta\left(\sigma_{f}\right)$ is low. In other words, the asymptotic compressive strength $\left(\sigma_{\infty}\right)$ can be safely estimated from the mean compressive strength of concrete samples whose the size $(L)$ is large enough to neglect the effect of the pore structure $\left(L_{m}\right)$.

\section{Extension to published datasets}

The size effects on the compressive strength $\left(\sigma_{f}\right)$ of our concretes were found to be in remarkable agreement with finite-size scaling predictions for both the mean value (Eq. (3)) and its standard deviation (Eq. (4)). In order to further validate our approach, we analyze below different experimental data coming from the literature. We focus (i) on strength datasets obtained from cylindrical samples with a height-to-diameter ratio $h / \phi=2$ similar to our conditions, and (ii) on the size effect on the mean strength $\left\langle\sigma_{f}\right\rangle$, as the limited number of independent tests in these previous works did not allow an analysis of strength variability. Because the qualities of the aggregates in these previous studies as well as their $W / C$ ratios are different from our study, a 
comparison of the asymptotic strength $\left(\sigma_{\infty}\right)$ is not possible. In addition, as the microstructural characteristics of the concretes, and particularly the pore content, were not detailed in these references, the role of these heterogeneities on compressive strength is not examined.

The first example considered refers to the tests carried out by Dehestani et al. [44] on cylindrical samples of self-consolidating concrete (SCC) under uniaxial compressive loading. In their work, three different concrete mixes were fabricated using three different $W / C$ ratios, but with a fixed maximum aggregate size of $12.5 \mathrm{~mm}$ and a cement proportion of $400 \mathrm{~kg} / \mathrm{m}^{3}$. Cylindrical specimen diameters were 50, 75, 100, and $150 \mathrm{~mm}$. The experimental results are summarized in Table 4 . Using $v_{F S}=1$, Eq. (3) well describes the size effect on compressive strength for these three SCC mixes (see Fig. 6a, b, c). A similar agreement is obtained for another strength data of normal-weight concrete provided by Muciaccia et al. [13], reported in Table 4 and Fig. 6d (same range of $W / C$ ratio). The corresponding asymptotic strength $\left(\sigma_{\infty}\right)$ and length scale $\left(L_{m}\right)$ for each of these four concrete mixtures were obtained from non-linear fits (Eq. (3)) and summarized in Table 4. As shown in this table, the $L_{m}$ value for the three SSC groups $M_{1}, M_{2}, M_{3}$ varies with the $W / C$ ratio, while the maximum aggregate size $\left(d_{g}\right)$ was kept constant. This is consistent with our previous observations presented in section 4, confirming that the size effect on compressive strength of concrete is not controlled by the aggregate size. As already mentioned above, the asymptotic strengths $\left(\sigma_{\infty}\right)$ reported in Table 4 are not constant and significantly different from our results. (see Table 3). This could be explained by different $\mathrm{W} / \mathrm{C}$ ratio and the use of high range water-reducing (HRWR) admixture type superplasticizer during the casting of the SSC groups (see Table 4 and Fig. $6 a, b, c)$. The main task of using a superplasticizer is to increase the fluidity of concrete by dispersing cement particles in paste without adding excess water [45-47]. For a given cement content, the use of superplasticizer enables to achieve a high concrete strength and durability due to the reduced amount of free water (low $W / C$ ratio) in the mixture $[45,48,49]$. In the work of Dehestani et al. [44], the three SSC mixtures were prepared with three different weight percentages of HRWR and three different $W / C$ ratios while keeping constant the cement content $\left(400 \mathrm{~kg} / \mathrm{m}^{3}\right)$ for 
all mixes. This could lead to a different nature of the binder matrix which caused the different values of asymptotic strength for the three SSC groups. For the results provided by Muciaccia et al. [13], a comparison of the asymptotic strength is not possible as well because the quality of aggregates as well as the $W / C$ ratio are different.

The second example considered is the size effect on the compressive strength of concrete observed by Sim et al. [50]. From their data, we considered here only three different concrete mixtures (named A43-0, S47-100, and N55-100) for which they performed mechanical test with the largest range of cylindrical sample sizes $(\phi=50,100,150,250,300,350,400 \mathrm{~mm})$ and with an aspect ratio of $h / \phi=2$. In accordance with ACI 213R-03 [51], mixtures A43-0, S47-100 and N55100 are classified following their densities $(\rho)$ as lightweight concrete, mortar and normal-weight concrete, respectively. The details of these concrete mixes are summarized in Table 5 . The A43-0 concrete mix used expanded clay granule as the aggregate, while the N55-100 mix used granite (coarse aggregate) and natural sand (fine aggregate) for casting. As the nature and the quality of the aggregates in the mixture are different from our work and previously detailed studies, a comparison of the asymptotic strength $\left(\sigma_{\infty}\right)$ is not possible. However, the maximum coarse aggregate size was fixed at $19 \mathrm{~mm}$ for both mixtures. Only natural sand with a maximum size of $5 \mathrm{~mm}$ was used to cast the S47-100 mixture. The size effect on mean compressive strength and the corresponding best-fit following Eq. (3) with $v_{F S}=1$ for the three experimental strength data are shown in Fig. 7a, b, c. The agreement with the scaling prediction (Eq. (3)) is remarkable. The corresponding $\sigma_{\infty}-$ and $L_{m}$ - values for these three concrete mixtures are presented in Table 5. We confirm an excellent collapse of all data (all sample sizes, all concrete mixtures) on a $\left[\left\langle\sigma_{f}\right\rangle v s .\left(L / L_{m}\right)^{-1 / v_{F S}}\right]$ plot (Fig. 7d), in full agreement with our previous results (Fig. 5a). A corresponding asymptotic strength of $\sigma_{\infty}=28.0 \pm 0.6(\mathrm{MPa})$ is obtained for these three concrete mixtures. This confirms that (i) the asymptotic strength $\sigma_{\infty}$ is not affected by the concrete mixture if using the same nature of aggregates for casting; and (ii) all the three concrete mixtures were batched for the same target concrete grade. As mentioned by Sim et al. [50] "The targeted compressive strength of all ready- 
mixed concrete batches was $35 \mathrm{MPa}$ ", meaning that, according to the EN 1992 regulation [3], the characteristic compressive strength for all three considered mixtures is $f_{c k}=f_{c m}-8=27 \mathrm{MPa}$. This $f_{c k}$-value is close to the asymptotic strength $\sigma_{\infty}$ extracted from the non-linear fits of experimental data (see Fig. 7d). In other words, the asymptotic strength $\sigma_{\infty}$ can be regarded as the characteristic strength $f_{c k}$ of concrete. This observation will be discussed further in section 6 .

The last example is offered by the experimental campaign of Blanks and McNamara [52] on large concrete cylinders. In their work, different concrete mixtures obtained by varying the maximum aggregate size $\left(d_{g}\right)$ were tested for various sizes with a constant aspect ratio $(h / \phi=2)$. We consider here only three concrete mixtures named B-8, B-9 and B-10 as they were associated with the widest range of sample size. Details on the mix proportions, specimen sizes and the corresponding 28-days mean compressive strength $\left\langle\sigma_{f}\right\rangle$ can be found in [52]. Fig. 8 shows the bestfitted finite-size scaling (Eq. (3), taking $v_{F S}=1$ ) for the mean compressive strength of the three considered concrete mixtures. The values of the asymptotic strength $\sigma_{\infty}$ as well as the length scale $L_{m}$ for the three considered concrete mixtures, obtained from non-linear fits of Eq. (3), are presented in Table 6. We observe that the scaling prediction (3) is in remarkable agreement with the published experimental data of [52]. Using $v_{F S}=1$ and the values of $L_{m}$ in Table 6, we plot all

strength data on a $\left[\left\langle\sigma_{f}\right\rangle\right.$ vs. $\left.\left(L / L_{m}\right)^{-1 / v_{F S}}\right]$ plot. As shown in Fig. 8d, a good collapse of all data (all sample size, all considered concrete mixtures) is obtained, with an asymptotic strength $\sigma_{\infty}=$ $22.4 \pm 0.3(\mathrm{MPa})$ independent of the concrete mixture. These observations, are consistent with our results (see section 4) and validate our theoretical framework.

Overall, the analysis of these previously published datasets is fully consistent with our results detailed in section 4, validating further our theoretical framework.

\section{Characteristic compressive strength of concrete}

Concrete design codes evaluate the characteristic compressive strength from subtracting the strength variability from the mean compressive strength obtained from a set of tested concrete 
specimens with a unique size (see Eq. (1)). However, due to the sample size effects on both the mean value and the associated variability of compressive strength (see section 4), this traditional estimation necessarily leads to size effects on the characteristic compressive strength $f_{c k}$ as estimated from Eq. (1). This questions the concept of characteristic strength itself, which should be representative of the material only and independent of external size. In this section, we show that the asymptotic strength, deduced from the external size effects towards the limit $L \rightarrow+\infty$, represents the genuine characteristic strength of concrete. We also propose some recommendations to determine accurately this asymptotic strength as well as to check the conformity of concrete with strength requirements.

\subsection{Asymptotic versus characteristic compressive strength}

Owing to the vanishing strength variability for a system of infinite size $(L \rightarrow+\infty)$, the asymptotic strength $\sigma_{\infty}$ (see Eq. (3)) can be considered as the genuine characteristic strength of concrete to be used to design large scale structures. However, as mentioned in section 1, the characteristic strength is instead classically calculated from the mean value and the standard deviation of compressive strength from the relation (1). In EN 1992 [3], the characteristic strength $\left(f_{c k}\right)$ is defined as that strength value below which only $5 \%$ of the compression tests are expected to fall. This corresponds to $\lambda=1.645$ in Eq. (1) (see Fig. 9). In ACI 318 [5], the tolerance is larger (10\%), corresponding to $\lambda=1.34$ (see Fig. 9).

Hence, from the mean strengths $\left\langle\sigma_{f}\right\rangle$ and standard deviations $\delta\left(\sigma_{f}\right)$ reported in Table 2, we can compute the characteristic strengths for each concrete mixture and sample size, as defined by the EN 1992 and the ACI 318 codes, using respectively $\lambda=1.645$ and $\lambda=1.34$ in Eq. (1).

Fig. 10 shows that the so-defined "characteristic" strength (i) differs for the three different concrete mixtures, and, more surprisingly, (ii) is sample size dependent. If point (i) could be expected at first glance, it results in our case only from different finite size effects for our three concretes (different $L_{m}$-values), as the asymptotic strength $\sigma_{\infty}$ is essentially independent of the 
concrete mix for the three materials prepared for this study (see Fig. 5). It is worth noting that this does not mean that $\sigma_{\infty}=36.9 \mathrm{MPa}$ would be a characteristic strength for all types of concrete. As already discussed in [15], the value of $\sigma_{\infty}$ will be of course different if we change the nature of either the fresh or hardened states of concrete (e.g. changing the type of aggregate or adding some kinds of concrete admixtures). This is illustrated by the fact that the asymptotic strength obtained for our concretes (Table 3), for the work of Sim et al. [50] (Table 5), or that of Blanks and McNamara [52] (Table 6), are significantly different, while essentially independent of the aggregate content within each of these studies.

Point (ii) strongly challenges the classical definition of the "characteristic" strength, which should be a size-independent material characteristic. This is in full contrast with our definition of the asymptotic strength $\sigma_{\infty}$, which is, by construction, sample size independent. The differences of the $f_{c k}$ values for the three concretes and different sample sizes obtained by applying Eq. (1) from our strength dataset are actually the perfect illustration of the limitation of the classical methodology used to determine the characteristic strength. In addition, we note that for most of the F-concrete and M-concrete dataset (one material, one sample size) the characteristic strength $\left(f_{c k}\right)$ calculated from the structural design codes are larger than the asymptotic strength $\sigma_{\infty}$, while an opposite result is observed for the C-concrete. This illustrates that the use of classical structural design codes and small concrete samples can lead to unreliable estimations of the asymptotic strength, relevant for large scale structures. These classical methods give sometimes unsafe estimations (e.g. F-and M-concretes) (see Fig. 10a and b), or occasionally too conservative ones (Cconcrete) (see Fig. 10c).

In most structural design codes, 150x300mm cylindrical samples $[3,5,6]$ (or 160x320mm in France [7]) are used as a standard to determine the characteristic compressive strength. Here, even though the 160x320-mm samples provide the values of the characteristic strength that are the closest to $\sigma_{\infty}$, the accuracy of the estimation of $\sigma_{\infty}$ depends on the confidence level chosen (i.e. the constant $\lambda$ in Eq. (1)), as well as on the concrete mix. Taking $f_{c m}=\left\langle\sigma_{f}\right\rangle, s=\delta\left(\sigma_{f}\right), v_{F S}=1$, a 
combination of Eq. (3) and Eq. (4) with Eq. (1) yields the following scaling for the characteristic strength $\left(f_{c k}\right)$ :

$$
f_{c k}=\sigma_{\infty} \times\left(\frac{L_{i}}{L}\right)+\sigma_{\infty}
$$

where $L_{i}=L_{m}-\lambda L_{\delta}$. Considering the corresponding strength $\sigma_{\infty}$ for each concrete mixture (Table 3), Eq. (5) fits well the $f_{c k}$ values for all concrete mixtures, and for both the EN 1992 [3] and ACI 318 [5] design codes (Fig. 10). For a given concrete mixture, the minimum sample size $\left(L_{\min }\right)$ that would allow a correct estimation of the asymptotic strength $\left(\sigma_{\infty} \pm 0.01 \sigma_{\infty}\right)$ while using classical design codes are reported in Table 3. These sample sizes are always larger than $160 \mathrm{~mm}$ and depend on the concrete mixture as well as the constant $\lambda$, i.e. on the code. In some cases, e.g. Fconcrete, to perform compression tests on samples large enough to give a correct estimate of $\sigma_{\infty}$ would require an unusually large loading capacity for laboratory testing (e.g., $37.5 \frac{\mathrm{N}}{\mathrm{mm}^{2}} \times$ $\left(\pi \times \frac{897^{2}}{4}\right) \mathrm{mm}^{2} \approx 24 \times 10^{6} \mathrm{~N}$ for F-concrete with the ACI 318 code).

This raises important problems while trying to estimate a reliable characteristic strength of concrete for large scales structural design from classical codes and a unique series of tests with a single sample size. To avoid sample size effects on strength, the sample size $L$ should be much larger than $L_{m}$ which itself depends on the microstructural characteristics (i.e. pore structure) of the hardened concrete.

On the other hand, the asymptotic strength $\left(\sigma_{\infty}\right)$ could be approximately determined by the mean strength $\left\langle\sigma_{f}\right\rangle$ of samples whose the size $(L)$ is much larger than the characteristic size of the pore structure $\left(L_{m}\right)$ (see Fig. 5a and section 4). Based on this idea, some recommendations for predicting the genuine characteristic strength of concrete, $\sigma_{\infty}$, are presented in the following section. 


\subsection{Recommendations for the determination of the asymptotic compressive strength}

As discussed above, the form of the finite-size scaling laws for both the mean strength (Eq. (3)), with a non-vanishing asymptotic strength $\left(\sigma_{\infty}\right)$, and the associated variability $(\delta(\sigma))$ vanishing at large scales, implies that $\sigma_{\infty}$ can be considered as the genuine characteristic strength $\left(f_{c k}\right)$ of concrete. We have also stressed that using a single concrete sample size for laboratory testing leads to different estimations of the characteristic strength from classical codes. Therefore, performing a series of compression tests with different sample sizes is highly recommended to reliably estimate the characteristic (asymptotic) compressive strength of concrete. We suggest below an experimental procedure:

1- Prepare cylindrical concrete samples with a length-to-diameter ratio of 2 and at least four different sizes. This condition is required to perform a good fit of the finite-size scaling laws (Eq. (3) and Eq. (4)) to the data in order to estimate the length scales $L_{m}$ and $L_{\delta}$ as well as the asymptotic strength $\sigma_{\infty}$. The number of test specimens in each size should be as large as possible, and not less than 30 specimens, following the standard ACI 318 [5].

2- The diameter of the smallest concrete cylinders should be at least 3 times the nominal maximum size of the coarse aggregate, following the regulations ASTM C31 [53], NF EN 206-1 [4] and NF EN 12390-1 [54]. This condition allows to reduce the "wall effect" that might happen when the maximum aggregate size is large relatively to the size of the mold, and to ensure the quality of the compaction procedure and the uniformity of the aggregate distribution in the samples.

3- The largest sample size should be as large as possible depending on the laboratory loading capacity. However, it should not be less than $160 \mathrm{~mm}$.

4- All the concrete samples must be cast, cured and tested under the same conditions.

5- Using $v_{F S}=1$ in Eq. (3), the asymptotic strength $\left(\sigma_{\infty}\right)$ is determined by a linear regression in a $\left[\left\langle\sigma_{f}\right\rangle\right.$ vs. $\left.L^{-1}\right]$ graph. The pertinence of the finite-size scaling can then be checked by plotting the strength variability $\delta(\sigma)$ as a function of $L^{-1}$ (see Eq. (4)).

A crucial advantage of such experimental program is that it provides a well-defined value of the characteristic (asymptotic) compressive strength of concrete which is no more affected by the 
sample size or the chosen $\lambda$-value. However, this requires a larger number of tests with samples of different sizes, making this procedure lengthy and costly. To circumvent this problem, a simple analysis of the pore structure of the concrete can be performed (see Appendix A). Indeed, Eq. (3) implies that the asymptotic strength will be correctly estimated from $\left\langle\sigma_{f}\right\rangle$ if $\frac{L_{m}}{L} \ll 0$.

In [15], we have shown that the length scale $L_{m}$ mainly depends on the intrinsic characteristic of the pore structure (air voids) in the hardened concrete. Fig. 11 shows the positive correlation between $L_{m}$ and the the maximum pore diameter $\left(d_{p, \max }\right)$ times the porosity $\left(p_{o}\right.$ in $\left.(\%)\right)$. A good linear regression $\left(R^{2}=0.85\right)$ is obtained:

$$
L_{m}=70 \times\left(\frac{p_{o}}{100} \times d_{p, \max }\right)
$$

This suggests an acceptance criterion for the minimum sample size with respect to the pore structure characteristics. Combining Eq. (3) with $v_{F S}=1$ and Eq. (6), this condition reads:

$$
L \geq \frac{0.7 \times\left(p_{o} \times d_{p, \max }\right)}{k}
$$

where $k$ can be seen as the acceptance constant, corresponding to the expected deviation of the average strength $\left\langle\sigma_{f}\right\rangle$ from the asymptotic strength $\sigma_{\infty}$. For example, to determine the characteristic asymptotic strength of C-concrete with an acceptance constant of $k=5 \%$, using the values of $p_{o}$ and $d_{p, \max }$ reported in Table A.1, the minimum sample size required is $L=120 \mathrm{~mm}$. This means that the mean compressive strength obtained on cylindrical samples with a diameter larger 120-mm can be regarded as an estimation of the characteristic strength of C-concrete with a confidence level of $95 \%$. On the other hand, with the same acceptance constant $k$, samples with a diameter of at least $464 \mathrm{~mm}$ would be needed to determine the characteristic strength of F-concrete. Although the asymptotic strength $\sigma_{\infty}$ is similar for the three different concrete mixtures (see Table 3 and Fig. 5), the sample size required for its estimation with the same accuracy, from a single series of tests, strongly varies with the material. This is another illustration of the role of the internal pore structure on the size effects on strength, while its impact on the asymptotic strength appears limited in our 
low-porosity concretes [15]. Consequently, if one uses only one sample size to estimate the characteristic strength of the material from laboratory testing, the sample size criterion (Eq. (7)) should be taken into account.

Quality control during construction is required to check the conformity of concrete to the strength requirements posed at the design stage. Usually, the acceptance strength criterion is derived from the characteristic strength determined from standard procedures [3], without paying attention to sample size effects or to the internal pore structure. However, based on the above discussion, we argue that, besides the strength criterion, an additional condition on the sample size for laboratory tests should be examined for the final acceptance decision. Hence, we propose the following stepby-step checking procedure:

1- Assign the strength grade of concrete $\left(f_{c k}\right)$, specified at the design stage, to the asymptotic strength $\left(\sigma_{\infty}\right)$ of the considered concrete.

2- Obtain the mean value $\left\langle\sigma_{f}\right\rangle$ and the standard deviation $\delta\left(\sigma_{f}\right)$ of the compressive strength of the considered concrete from a series of at least 30 compression tests carried out on sample cylinders of diameter $L$.

3- Perform an image analysis of internal sections on virgin concrete samples to estimate the porosity $\left(p_{o}\right)$ and the pore maximum diameter $\left(d_{p, \max }\right)$ (see Appendix A). A minimum of three sections including one vertical and two horizontal sections (see Fig. A.1a) for each sample are recommended. In the case of concrete samples fabricated from different batches, one sample in each batch has to be selected and analyzed. Note that other methods and techniques can be used alternatively to determine the porosity and the pore size distribution of concrete or of other cement based materials, such as the fluid displacement method [55], mercury intrusion porosimetry (MIP) [56-61], capillary condensation measurement $[61,62]$, and back scattered electron microscopy [6367]. All these methods can be used to determine the porosity.

4- Calculate the minimum required average strength $\left(f_{m r}\right)$ of the considered concrete at the sample size $L$ from the equations (3) and (6) with $v_{F S}=1$, based on the values of the required asymptotic 
strength, $\sigma_{\infty}$ (step 1), of the porosity, $p_{o}$ (step 3) and of the pore maximum diameter, $d_{p, \max }$ (step 3), yielding:

$$
f_{m r}=\sigma_{\infty}\left[\frac{0.7 \times\left(p_{o} \times d_{p, \max }\right)}{L}+1\right]
$$

where the porosity $p_{o}$ is expressed in $\%$.

5- Compare the experimental mean strength $\left\langle\sigma_{f}\right\rangle$ (obtained at the step 2) with the minimum required average strength $f_{m r}$ (calculated by using Eq. (8)). If $\left\langle\sigma_{f}\right\rangle \geq f_{m r}$, we can state that the examined concrete complies with the strength requirements.

We note that the relation between the length scale $L_{m}$ and the characteristics of the pore structure (Fig. 11) has only been validated for our low-porosity concrete. It is doubtful that it would hold for large porosity concretes, for which the pore structure is much more complex (non-spherical, interconnected pores) and the direct impact of porosity on strength is strong $([57,68-70])$. Therefore, the above procedure should be applied only for normal-weight concretes with a total porosity of less than $10 \%$. In addition, a smaller sample size $L$ implies a larger "correcting factor" $k$ in the relation (7) as well as a larger strength variability $\delta(\sigma)$ at this size. We therefore recommend using cylindrical samples with a diameter larger than $110 \mathrm{~mm}$.

Two examples illustrating the application of the above procedure are presented below.

\section{Application examples}

1. In the first example (Table 7), we check the conformity of our three concrete mixtures with the strength class C35/45 expressed in EN 1992 [3]. The values of parameters obtained for the 160x320mm samples are used for this example. As shown in Table 7, all of the three concrete mixtures have an experimental mean compressive strength $\left\langle\sigma_{f}\right\rangle$ larger than the minimum required average strength $f_{m r}$ calculated by using Eq. (8). Therefore, we can conclude that these three mixtures comply with the strength requirements for the strength class $\mathrm{C} 35 / 45$. In this example, the C-mixture provides the closest mean strength value to the required value of strength class C35/45 in comparison with the other mixtures. This means that a coarser concrete mixture, having a lower porosity in its hardened form, will comply better the targeted characteristic strength than finer mixtures. 
2. For the second example (Table 8), based on the original data of the C-160x320mm samples (Case 1), two additional cases are considered after changing either the value of porosity (Case 2) or the value of the mean compressive strength (Case 3). As the results presented in Table 8, the two last cases do not comply with the strength requirement for the strength class C35/45. Although Case 2 has the same mean strength for $160 \times 320 \mathrm{~mm}$ samples as experimental Case 1, the strength requirement is not satisfied for Case 2, owing to a larger porosity. This results from the fact that a larger porosity means stronger size effects on strength, hence a larger value of the minimum average strength required at a fixed sample size. The production of normal-weight concrete with a porosity as small as possible is an important goal to achieve a good quality of concrete as well as to be able to correctly estimate the asymptotic strength for laboratory samples. Case 3, characterized by an unchanged porosity but a smaller mean strength than Case 1, also fails the strength requirement. This illustrates the fact that both the strength and the sample size criteria must be examined for the acceptance decision.

\section{Conclusion}

In this paper, from an experimental study of the statistical size effects on the compressive strength of concrete as well as an analysis of published strength data: we (i) discussed the definition of the characteristic compressive strength of concrete when size effects on strength are taken into account; and (ii) proposed to revise the procedures to estimate this characteristic strength and to check the conformity of concrete to the strength requirements defined at the design stage. The following main conclusions can be drawn:

1. The observed size effects on both the mean compressive strength and the standard deviation of our concretes can be rationalized from finite-size effects associated with an interpretation of the compressive failure of concrete as a critical transition. This implies that a very large system system $(L \rightarrow+\infty)$ has a non-vanishing strength $\left(\sigma_{\infty}>0\right)$ but its strength variability vanishes $\left(\delta\left(\sigma_{f}\right) \rightarrow 0\right)$.

2. Owing to these vanishing intrinsic fluctuations of strength at large scales $\left(\delta\left(\sigma_{f}\right)_{L \rightarrow+\infty} \rightarrow 0\right)$, the asymptotic strength $\left(\sigma_{\infty}\right)$ can be considered as the genuine characteristic compressive 
strength of concrete. Therefore, an experimental study conducted on a series of at least four different sample sizes is strongly recommended to allow an accurate determination of the size effects on strength, hence of the characteristic compressive strength of concrete.

3. For low-porosity concretes, the pore structure of the hardened concrete samples plays a key role in controlling the size effects on strength but does not have a significant impact on the asymptotic compressive strength. A concrete with a lower porosity will be less affected by size effects on compressive strength than a concrete with a larger porosity. Another important consequence is that, if one wants to estimate the characteristic (asymptotic) strength of the material from a series of tests with a single sample size, a condition on this size with respect to the characteristic scale of the pore structure should be fulfilled.

4. This characteristic scale of the pore structure in a hardened concrete sample can be estimated from the product of the maximum pore diameter and the total porosity. In order to determine these two parameters, we proposed a simple image analysis procedure on internal sections of concrete samples, but other techniques can be used to measure these parameters. This procedure was tested so far only on a limited number of different concrete mixtures. An extension of this work to other concrete materials with various microstructures would be necessary to refine this estimation. 


\section{Appendix A. Characterization of the pore structure}

The strength of concrete can be significantly affected by the volume of all pores: capillary pores, gel pores and air voids (entrained and entrapped air voids) [2,61]. Hence, the porosity and size distribution of pores must be quantified [71]. Mehta and Monteiro [1] noted that "entrapped and entrained air voids in the hydrated cement paste are much bigger than the capillary voids, and are capable of adversely affecting the strength". Actually, there is no consensus on the role of the capillary pores of the hardened concrete on compressive strength (e.g. [72-74]). In addition, due to their small sizes (ranging from $0.5 \mathrm{~nm}$ to $1 \mu \mathrm{m}$ ), gel and capillary pores are hard to detect by optical methods. Thus, we just focus here on air voids (referred as pores in the following). In the present work, an image analysis procedure was used to characterize the pore structure of our undamaged concrete samples based on the procedure presented in $[75,76]$.

First, one sample was selected for each size and each concrete mixture (for a total 12 samples used for this image analysis) and then cut into four pieces (see Fig. A.1a). To remove any scratching on the sample surfaces due to the sawing process, the surfaces were ground flat using hand pressure on a water-cooler wheel topped with more and more grit size of metal-bonded diamond plates [75]. Then, these surfaces were polished by using successively finer grit resin-bonded diamond plates to remove any striations from the grinding materials (see Fig. A.1b). After that, the sample surfaces were treated to enhance the contrast between pores and other components (aggregates, cement paste). This was done by filling the depressions with a calcium carbonate paste.

After this preparation, the sample surfaces were scanned by a flatbed scanner at a resolution of 1200dpi (equivalent to $21.17 \mu \mathrm{m} / \mathrm{pixel}$ ). Thanks to the white color of the calcium carbonate paste, the pores were easily distinguished from the solid phases (aggregates and hardened cement paste) after applying a manual contrast enhancement (Fig. A.1c) and thresholding (Fig. A.1d). Fig. A.2 illustrates a comparison of the pore structures for three different concrete mixtures. 
Whereas gel and capillary voids are irregular in shape, air voids are generally spherical-like $[1,2]$. This is consistent with the cross-sections of Fig. A.2. Therefore, to obtain the threedimensional (3D) pore size distribution, a stereological $2 \mathrm{D} \rightarrow 3 \mathrm{D}$ conversion method for a polydispersed system of spheres $[77,78]$ was applied in this work. From the binary image of pores (Fig. A.2), the cross-sectional areas of individual pores were calculated and classified into $n$ size (diameter) intervals. A value of $n=14$ was chosen to obtain a large enough number of pores in each interval. We noted $\left(N_{A}\right)_{i}$ the number of pores per unit area in each size interval $i$. The corresponding diameter range for the $i^{t h}$ interval is $\left[d_{p m} \times 10^{-0.1(i-2)}, d_{p m} \times 10^{-0.1(i-1)}\right]$, where $d_{p m}$ is the largest 2D diameter of an equivalent circular pore. Following the Saltykov's method $[77,78]$, we assumed that the largest 2D pore areas correspond to the largest spheres. It means that the diameter of the largest $2 \mathrm{D}$ pore area is equal to that of the largest $3 \mathrm{D}$ spherical pore in the sample volume. Smaller 2D areas of diameter $\left(d_{p}\right)_{i}$ can result from cutting the spheres having a diameter $\left(d_{p}\right)_{j}$ larger than or equal to $\left(d_{p}\right)_{i}$. Then, from the geometric probability distribution of the distances from a random cutting plane to the centers of spheres, we obtain the expression:

$$
\left(N_{v}\right)_{j}=\frac{1}{\left(d_{p}\right)_{j}} \sum_{i=j}^{k} \alpha_{i}\left(N_{A}\right)_{i}
$$

where the $j$ 's refer to sphere diameters and the $i^{\prime}$ s refer to area diameters; $i$ and $j$ are integer values from 1 to $n$, and $n$ is equal to the total number of diameter class intervals; $\left(N_{v}\right)_{j}$ is the number of spherical pores per unit volume in the diameter class $j ;\left(d_{p}\right)_{i}$ is the diameter of the largest areas observed on the cutting plane, this diameter depends on the number of size class intervals, and corresponds to the sphere diameter class $j ; \sum_{j}\left(N_{A}\right)_{i, j}$ represents the number per unit area of pore diameter class $\left(d_{p}\right)_{i}$, which can be obtained from spheres of different diameter $\left(d_{p}\right)_{j}$; $\alpha_{i}$ is the coefficient corresponding to the area's diameter class $\left(d_{p}\right)_{i}$, this coefficient can be obtained from the probability of a cutting plane intersecting a sphere of diameter $\left(d_{p}\right)_{j}$ to yield 
areas of diameter $\left(d_{p}\right)_{i}$. Using the values of the coefficients $\alpha_{i}$ given in [77-79], the 3D pore size distribution was determined for each concrete sample.

Fig. A.3 presents the (cumulative) probability distribution of pore sizes for different concrete samples. We observe: (i) an absence of sample size effect on the pore size distribution for a given type of concrete; (ii) that the pore size distributions have a power law shape, $P\left(>d_{p}\right) \sim d_{p}{ }^{-\alpha}$, with an exponent $\alpha$ slightly varying with the material (see Fig. A.3).

From these distributions, the average diameter and the total porosity were estimated and reported in Table A.1 for the different concrete samples. We note that the number of pore per $\mathrm{m}^{3}$, the mean as well as the maximum pore diameter, and the total porosity, all decrease with increasing aggregate size (see Fig. A.2 and Table A.1). In this study, the maximum pore diameter, $d_{p, m a}$, was calculated by averaging the values of $d_{p, m}$ of all four different sections (Fig. A.1a) of a given size, and of all sections and samples (whatever the size) of a given concrete mixture.

The presence of pores in hardened concrete is related to the water and cement contents of the mix. Larger cement and water contents imply a larger ability for holding the free water in the hardened cement paste after the hydration process, hence more air voids (pores) in the hardened concrete [1]. This explains why the F-concrete, which has the largest water-to-cement ratio, shows the largest pore sizes and porosity (see Table A.1) as well as the largest moisture. When large enough, porosity is known to directly impact the compressive strength of concrete $[57,68-70]$. However, as the porosity of our samples always remained below 5\% (Table A.1), it did not impact significantly the asymptotic strength $\left(\sigma_{\infty}\right)$ of our materials (see Table 3 ). 


\section{Acknowledgement}

This work was supported by the program of AGIR-POLE-PAGE from the University of Grenoble Alpes (UGA), France. The authors are thankful to technicians of UGA and USMB for technical assistance.

\section{References}

[1] P.K. Mehta, P.J.M. Monteiro, Concrete: microstructure, properties, and materials, Third, McGraw-Hill, 2006. https://doi.org/10.1036/0071462899.

[2] A.M. Neville, J.J. Brooks, Properties of concrete, 4th ed., Pearson Education Limited, 2010. https://doi.org/10.4135/9781412975704.n88.

[3] EN 1992, Eurocode 2: Design of concrete structures - Part 1-1: General rules and rules for buildings, European Committee for Standardization, 2004.

[4] NF EN 206-1, Béton - Partie 1: Spécification, performances, production et conformité, Association Française de Normalisation (AFNOR), 2004.

[5] ACI 318-05, Building Code Requirements for Structural Concrete and Commentary, American Concrete Institute, 2005.

[6] ASTM C39/C39M-14, Standard Test Method for Compressive Strength of Cylindrical Concrete Specimens, ASTM Int. (2014) 1-7. https://doi.org/10.1520/C0039_C0039M-14.

[7] NF EN 12390-3, Essais pour béton durci - Partie 3: Résistance à la compression des éprouvettes, Association Française de Normalisation (AFNOR), 2012.

[8] Z.P. Bazant, J. Planas, Fracture and size effect in concrete and other quasibrittle materials, CRC Press, Boca Raton, Florida, USA, 1998.

[9] S.L. Burtscher, J. Kollegger, Size-effect experiments on concrete in compression, Struct. Concr. 4 (2003) 163-174.

[10] J. Ozbolt, R. Eligehausen, Size effect in concrete and reinforced concrete structures, Fract. Mech. Concr. Struct. (1995) 665-674.

[11] Z.P. Bazant, Size Effect on Structural Strength: A Review, Arch. Appl. Mech. 69 (1999) 703-725. https://doi.org/10.1007/s004190050252.

[12] Z.P. Bazant, Size effect in tensile and compression fracture of concrete structures: Computational modeling and design, Fract. Mech. Concr. Struct. Proceeding (1998) 19051922.

[13] G. Muciaccia, G. Rosati, G. Di Luzio, Compressive failure and size effect in plain concrete cylindrical specimens, Constr. Build. Mater. $137 \quad$ (2017) 185-194. https://doi.org/10.1016/j.conbuildmat.2017.01.057.

[14] J.R. del Viso, J.R. Carmona, G. Ruiz, Shape and size effects on the compressive strength of high-strength concrete, Cem. Concr. Res. 38 (2008) 386-395. https://doi.org/10.1016/j.cemconres.2007.09.020.

[15] C.C. Vu, J. Weiss, O. Plé, D. Amitrano, D. Vandembroucq, Revisiting statistical size effects on compressive failure of heterogeneous materials, with a special focus on concrete, J. Mech. Phys. Solids. 121 (2018) 47-70. https://doi.org/10.1016/j.jmps.2018.07.022.

[16] J. Weiss, L. Girard, F. Gimbert, D. Amitrano, D. Vandembroucq, (Finite) statistical size effects on compressive strength, Proc. Natl. Acad. Sci. U. S. A. 111 (2014) 6231-6236. https://doi.org/10.1073/pnas.1403500111.

[17] L. Girard, J. Weiss, D. Amitrano, Damage-cluster distributions and size effect on strength in compressive failure, Phys. Rev. Lett. $108 \quad$ (2012) 1-5. 
https://doi.org/10.1103/PhysRevLett.108.225502.

[18] L. Girard, D. Amitrano, J. Weiss, Failure as a critical phenomenon in a progressive damage model, J. Stat. Mech. Theory Exp. 2010 (2010) P01013. https://doi.org/10.1088/17425468/2010/01/P01013.

[19] C. Vu, D. Amitrano, O. P1, Compressive Failure as a Critical Transition: Experimental Evidence and Mapping onto the Universality Class of Depinning, Phys. Rev. Lett. 122 (2019) 6. https://doi.org/10.1103/PhysRevLett.122.015502.

[20] NF EN 197-1, Ciment -Partie 1: Compostition, spécifications et critères de conformité des ciments courants, Association Française de Normalisation (AFNOR), 2012.

[21] NF EN 12620, Granulats pour béton, Association Française de Normalisation (AFNOR), 2008.

[22] NF EN 1097-5, Essais pour déterminer les caractéristiques mécaniques et physiques des granulats - Partie 5: détermination de la teneur en eau par séchage en étuve ventilée, Association Française de Normalisation (AFNOR), 2008.

[23] NF EN 933-1, Essais pour déterminer les caractéristiques géométriques des granulats - Partie 1: détermination de la granularité - Analyse granulométrique par tamisage, Association Française de Normalisation (AFNOR), 2012.

[24] NF EN 196-1, Méthodes d'essais des ciments - Partie 1: détermination des résistances, Association Française de Normalisation (AFNOR), 2016.

[25] G. Dreux, F. Gorisse, Composition des bétons : méthode Dreux Gorisse, bilan de cinq années d'application en Côte d'Ivoire, Annales de l'Institut Technique du bâtiment et des Travaux Publiques, 1983.

[26] NF EN 12390-2, Essais pour béton durci - Partie 2: Confection et conservation des éprouvettes pour essais de résistance, Association Française de Normalisation (AFNOR), 2012.

[27] NF EN 12390-4, Essais pour béton durci - Partie 4: Résistance à la compression Caractéristiques des machines d'essai, Association Française de Normalisation (AFNOR), 2000. https://doi.org/10.1017/CBO9781107415324.004.

[28] J. Mazars, G. Pijaudier-Cabot, C. Saouridis, Size effect and continuous damage in cementitious materials, Int. J. Fract. 51 (1991) 159-173. https://doi.org/10.1007/BF00033976.

[29] D. Jeulin, M. Ostoja-Starzewski, Mechanics of random and multiscale microstructures, 1st ed., Springer-Verlag Wien, 2001. https://doi.org/10.1007/978-3-7091-2780-3.

[30] S. Torquato, Random heterogeneous media: Microstructure and improved bounds on effective properties, Appl. Mech. Rev. 44 (1991) 37-76. https://doi.org/10.1115/1.3119494.

[31] NF EN 12390-7, Essais pour béton durci - Partie 7: Masse volumique du béton durci, Association Française de Normalisation (AFNOR), 2012.

[32] H.K. Hilsdorf, A method to estimate the water content of concrete shields, Nucl. Eng. Des. 6 (1967) 251-263. https://doi.org/10.1016/0029-5493(67)90022-2.

[33] F.M. Bartlett, J.G. MacGregor, Effect of Moisture Condition on Concrete Core Strengths, ACI Mater. J. 91 (1994) 227-236.

[34] Ifsttar, Caractérisation du béton durci: Essais liés à a corrosion des armatures, (1994) 15.

[35] S.E. Pihlajavaara, A review of some of the main results of a research on the ageing phenomena of concrete: Effect of moisture conditions on strength, shrinkage and creep of mature concrete, Cem. Concr. Res. 4 (1974) 761-771. https://doi.org/10.1016/00088846(74)90048-9.

[36] Z.P. Bazant, Size Effect in Blunt Fracture: Concrete, Rock, Metal, J. Eng. Mech. 110 (1984) 518-535. https://doi.org/10.1061/(ASCE)0733-9399(1984)110:4(518). 
[37] W. Weibull, A statistical theory of the strength of materials, R. Swedish Inst. Eng. Res. 151 (1939) 45.

[38] W. Weibull, A Statistical Distribution Function of Wide Applicability, J. Appl. Mech. 18 (1951) 293-297.

[39] D. Ertas, M. Kardar, Critical dynamics of contact line depinning, Phys. Rev. E. 49 (1994) 2532-2535. https://doi.org/10.1103/PhysRevE.49.R2532.

[40] D.S. Fisher, Collective ransport in random media: from superconductors to earthquakes, Phys. Rep. 301 (1998) 113-150.

[41] S. Zapperi, Current challenges for statistical physics in fracture and plasticity, Eur. Phys. J. B. 85 (2012) 329. https://doi.org/10.1140/epjb/e2012-30471-9.

[42] A. Carpinteri, B. Chiaia, G. Ferro, Size effects on nominal tensile strength of concrete structures: multifractality of material ligaments and dimensional transition from order to disorder, Mater. Struct. 28 (1995) 311-317. https://doi.org/10.1007/BF02473145.

[43] Z.P. Bazant, Scaling theory for quasibrittle structural failure., Proc. Natl. Acad. Sci. U. S. A. 101 (2004) 13400-13407. https://doi.org/10.1073/pnas.0404096101.

[44] M. Dehestani, I.M. Nikbin, S. Asadollahi, Effects of specimen shape and size on the compressive strength of self-consolidating concrete (SCC), Constr. Build. Mater. 66 (2014) 685-691. https://doi.org/10.1016/j.conbuildmat.2014.06.008.

[45] P.C. Aïtcin, R.J. Flatt, Science and technology of concrete admixtures, 2015. https://doi.org/10.1016/C2015-0-00150-2.

[46] K. Yoshioka, E.I. Tazawa, K. Kawai, T. Enohata, Adsorption characteristics of superplasticizers on cement component minerals, Cem. Concr. Res. 32 (2002) 1507-1513. https://doi.org/10.1016/S0008-8846(02)00782-2.

[47] B. Łaźniewska-Piekarczyk, The influence of selected new generation admixtures on the workability, air-voids parameters and frost-resistance of self compacting concrete, Constr. Build. Mater. 31 (2012) 310-319. https://doi.org/10.1016/j.conbuildmat.2011.12.107.

[48] J. Gołaszewski, Influence of cement properties on new generation superplasticizers performance, Constr. Build. Mater. $35 \quad$ (2012) 586-596. https://doi.org/10.1016/j.conbuildmat.2012.04.070.

[49] F. Puertas, H. Santos, M. Palacios, S. Martınez-Ramirez, Polycarboxylate superplasticiser admixtures: effect on hydration, microstructure and rheological behaviour in cement pastes, Adv. Cem. Res. 17 (2005) 77-89.

[50] J. Il Sim, K.H. Yang, H.Y. Kim, B.J. Choi, Size and shape effects on compressive strength of lightweight concrete, Constr. Build. Mater. $38 \quad$ (2013) 854-864. https://doi.org/10.1016/j.conbuildmat.2012.09.073.

[51] ACI 213R-03, Guide for structural lightweight aggregate concrete, Am. Concr. Inst. (2003). https://doi.org/10.1016/0262-5075(79)90004-6.

[52] R.F. Blanks, C. McNamara, Mass concrete tests in large cylinders, J. Am. Concr. Inst. 31 (1935) 280-303.

[53] ASTM C31/C31M-03, Standard Practice for Making and Curing Concrete Test Specimens in the Field, ASTM Int. (2003) 1-5.

[54] NF EN 12390-1, Essais pour béton durci - Partie 1: Forme, dimensions et autres exigences relatives, Association Française de Normalisation (AFNOR), 2012.

[55] B.B. Das, B. Kondraivendhan, Implication of pore size distribution parameters on compressive strength, permeability and hydraulic diffusivity of concrete, Constr. Build. Mater. 28 (2012) 382-386. https://doi.org/10.1016/j.conbuildmat.2011.08.055.

[56] C. Gallé, Effect of drying on cement-based materials pore structure as identified by mercury intrusion porosimetry - A comparative study between oven-, vacuum-, and freeze-drying, 
Cem. Concr. Res. 31 (2001) 1467-1477. https://doi.org/10.1016/S0008-8846(01)00594-4.

[57] R. Kumar, B. Bhattacharjee, Porosity, pore size distribution and in situ strength of concrete, Cem. Concr. Res. 33 (2003) 155-164. https://doi.org/10.1016/S0008-8846(02)00942-0.

[58] R. Kumar, B. Bhattacharjee, Assessment of permeation quality of concrete through mercury intrusion porosimetry, Cem. Concr. Res. 34 (2004) 321-328. https://doi.org/10.1016/j.cemconres.2003.08.013.

[59] R.A. Cook, K.C. Hover, Mercury porosimetry of cement-based materials and associated correction factors, Constr. Build. Mater. 7 (1993) 231-240. https://doi.org/10.1016/09500618(93)90007-Y.

[60] R.A. Cook, K.C. Hover, Mercury porosimetry of hardened cement pastes, Cem. Concr. Res. 29 (1999) 933-943. https://doi.org/10.1016/S0008-8846(99)00083-6.

[61] S. Diamond, A critical comparison of mercury porosimetry and capillary condensation pore size distributions of portland cement pastes, Cem. Concr. Res. 1 (1971) 531-545. https://doi.org/10.1016/0008-8846(71)90058-5.

[62] R.S. Mikhail, L.E. Copeland, S. Brunauer, Pore structures and surface areas of hardened portland cement pastes by nitrogen adsorption, Can. J. Chem. 42 (1964) 426-438. www.nrcresearchpress.com.

[63] S.I. Igarashi, A. Watanabe, M. Kawamura, Evaluation of capillary pore size characteristics in high-strength concrete at early ages, Cem. Concr. Res. 35 (2005) 513-519. https://doi.org/10.1016/j.cemconres.2004.06.036.

[64] D.A. Lange, H.M. Jennings, S.P. Shah, Image analysis techniques for characterization of pore structure of cement-based materials, Cem. Concr. Res. 24 (1994) 841-853. https://doi.org/10.1016/0008-8846(94)90004-3.

[65] S. Diamond, Aspects of concrete porosity revisited, Cem. Concr. Res. 29 (1999) 1181-1188. https://doi.org/10.1016/S0008-8846(99)00122-2.

[66] P. Soroushian, M. Elzafraney, A. Nossoni, Specimen preparation and image processing and analysis techniques for automated quantification of concrete microcracks and voids, Cem. Concr. Res. 33 (2003) 1949-1962. https://doi.org/10.1016/S0008-8846(03)00219-9.

[67] H.S. Wong, M.K. Head, N.R. Buenfeld, Pore segmentation of cement-based materials from backscattered electron images, Cem. Concr. Res. 36 (2006) 1083-1090. https://doi.org/10.1016/j.cemconres.2005.10.006.

[68] X. Chen, S. Wu, J. Zhou, Influence of porosity on compressive and tensile strength of cement

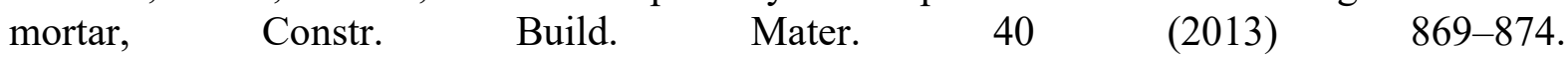
https://doi.org/10.1016/j.conbuildmat.2012.11.072.

[69] S. Kolias, Investigation of the possibility of estimating concrete strength by porosity measurements, Mater. Struct. 27 (1994) 265-272. https://doi.org/10.1007/BF02473043.

[70] C. Lian, Y. Zhuge, S. Beecham, The relationship between porosity and strength for porous concrete, Constr. Build. Mater. $25 \quad$ (2011) 4294-4298. https://doi.org/10.1016/j.conbuildmat.2011.05.005.

[71] P.C. Fonseca, G.W. Scherer, An image analysis procedure to quantify the air void system of mortar and concrete, Mater. Struct. 48 (2015) 3087-3098. https://doi.org/10.1617/s11527014-0381-9.

[72] H. Zhao, Q. Xiao, D. Huang, S. Zhang, Influence of pore structure on compressive strength of cement mortar., Sci. World J. 2014 (2014) 1-12. https://doi.org/10.1155/2014/247058.

[73] B. Kondraivendhan, B. Bhattacharjee, Effect of age and water-cement ratio on size and dispersion of pores in ordinary portland cement paste, ACI Mater. J. 107 (2010) 147-154.

[74] L. Zingg, M. Briffaut, J. Baroth, Y. Malecot, Influence of cement matrix porosity on the triaxial behaviour of concrete, Cem. Concr. Res. 80 (2016) 52-59. 
https://doi.org/10.1016/j.cemconres.2015.10.005.

[75] ASTM C 457/C 457M-16, Standard Test Method for Microscopical Determination of Parameters of the Air-Void System in Hardened Concrete, ASTM Int. (2016). www.astm.org.

[76] U.H. Jakobsen, C. Pade, N. Thaulow, D. Brown, S. Sahu, O. Magnusson, S. De Buck, G. De Schutter, Automated air void analysis of hardened concrete - a Round Robin study, Cem. Concr. Res. 36 (2006) 1444-1452. https://doi.org/10.1016/j.cemconres.2006.03.005.

[77] S.A. Saltykov, The determination of the size distribution of particles in an opaque material from a measurement of the size distribution of their sections, Springer Berlin Heidelberg, 1967. https://doi.org/10.1007/978-3-642-88260-9_31.

[78] E.E. Underwood, Quantitative stereology, Addison-Wesley Pub. Co., 1970.

[79] H. Shen, S.M. Oppenheimer, D.C. Dunand, L.C. Brinson, Numerical modeling of pore size and distribution in foamed titanium, Mech. Mater. 38 (2006) 933-944. https://doi.org/10.1016/j.mechmat.2005.06.027.

[80] S.U. Pillai, D. Menon, Reinforced Concrete Design, 3rd ed., Tata McGraw-Hill Education Pvt. Ltd., 2009. 
Table captions

Table 1. Mixture proportions for $1 \mathrm{~m} 3$ of concrete, density and moisture content

\begin{tabular}{|c|c|c|c|c|c|c|c|c|c|c|c|c|}
\hline \multirow[t]{2}{*}{$\begin{array}{l}\text { Concrete } \\
\text { mixture }\end{array}$} & \multirow[t]{2}{*}{$\begin{array}{r}\text { Water } \\
\text { (kg) }\end{array}$} & \multirow[t]{2}{*}{$\begin{array}{r}\text { Cement } \\
(\mathrm{kg})\end{array}$} & \multirow[t]{2}{*}{$\mathbf{W} / \mathbf{C}$} & \multirow[t]{2}{*}{$\begin{array}{r}\text { Sand } \\
(\mathrm{kg})\end{array}$} & \multirow[t]{2}{*}{$\begin{array}{r}\text { Medium } \\
\text { aggregate } \\
(\mathrm{kg})\end{array}$} & \multirow[t]{2}{*}{$\begin{array}{r}\text { Coarse } \\
\text { aggregate } \\
(\mathrm{kg})\end{array}$} & \multirow[t]{2}{*}{$\begin{array}{r}\text { Maximum } \\
\text { aggregate size, } \\
d_{g}(\mathrm{~mm})\end{array}$} & \multirow[t]{2}{*}{$\begin{array}{r}\text { Finesse } \\
\text { modulus }\end{array}$} & \multicolumn{2}{|c|}{$\begin{array}{r}\text { Density, } \\
\rho\left(\mathrm{kg} / \mathrm{m}^{3}\right)\end{array}$} & \multicolumn{2}{|c|}{$\begin{array}{c}\text { Moisture } \\
\text { content, } \\
w_{c}(\%)\end{array}$} \\
\hline & & & & & & & & & Mean & SD & Mean & SD \\
\hline F & 225 & 450 & 0.50 & 1350 & 0 & 0 & 3.15 & 3.24 & 2184.0 & 20.5 & 5.3 & 0.4 \\
\hline M & 195 & 335 & 0.58 & 800 & 1065 & 0 & 16 & 6.95 & 2391.4 & 14.7 & 3.2 & 0.2 \\
\hline $\mathrm{C}$ & 195 & 335 & 0.58 & 800 & 0 & 1065 & 25 & 9.21 & 2403.8 & 18.2 & 3.2 & 0.3 \\
\hline
\end{tabular}

Table 2. Compressive strength of concrete samples

\begin{tabular}{|c|c|c|c|c|c|}
\hline \multirow{2}{*}{$\begin{array}{l}\text { Concrete } \\
\text { group }\end{array}$} & \multirow{2}{*}{$\begin{array}{l}\text { Specimen size, } \\
\phi \times h(\mathrm{~mm} \times \mathrm{mm})\end{array}$} & \multicolumn{4}{|c|}{ Compressive strength, $\sigma_{f}(\mathrm{MPa})$} \\
\hline & & Mean & SD & Skewness & Kurtosis \\
\hline \multirow{4}{*}{$\mathrm{F}$} & $40 \times 80$ & 56.4 & 7.9 & -0.21 & -0.74 \\
\hline & $70 \times 140$ & 49.7 & 5.3 & 0.08 & -0.88 \\
\hline & $110 \times 220$ & 44.3 & 2.4 & -0.12 & 0.06 \\
\hline & $160 \times 320$ & 41.9 & 2.4 & 0.29 & -0.94 \\
\hline \multirow{4}{*}{ M } & $40 \times 80$ & 49.6 & 6.2 & 0.31 & -0.73 \\
\hline & $70 \times 140$ & 45.2 & 4.2 & -0.58 & -0.64 \\
\hline & $110 \times 220$ & 41.9 & 1.9 & 0.04 & -0.62 \\
\hline & $160 \times 320$ & 39.2 & 1.8 & -0.14 & -0.66 \\
\hline \multirow{4}{*}{$\mathrm{C}$} & $40 \times 80$ & 39.5 & 4.6 & 0.47 & -0.27 \\
\hline & $70 \times 140$ & 40.0 & 6.3 & -0.05 & -0.86 \\
\hline & $110 \times 220$ & 37.1 & 2.7 & -0.35 & -0.66 \\
\hline & $160 \times 320$ & 36.7 & 1.4 & -0.59 & -0.05 \\
\hline
\end{tabular}


Table 3. Finite-size scaling parameters (Eq. (3) and (4)) (after [15]), and estimated parameters of the characteristic strength expressed according to EN-1992 and ACI 318.

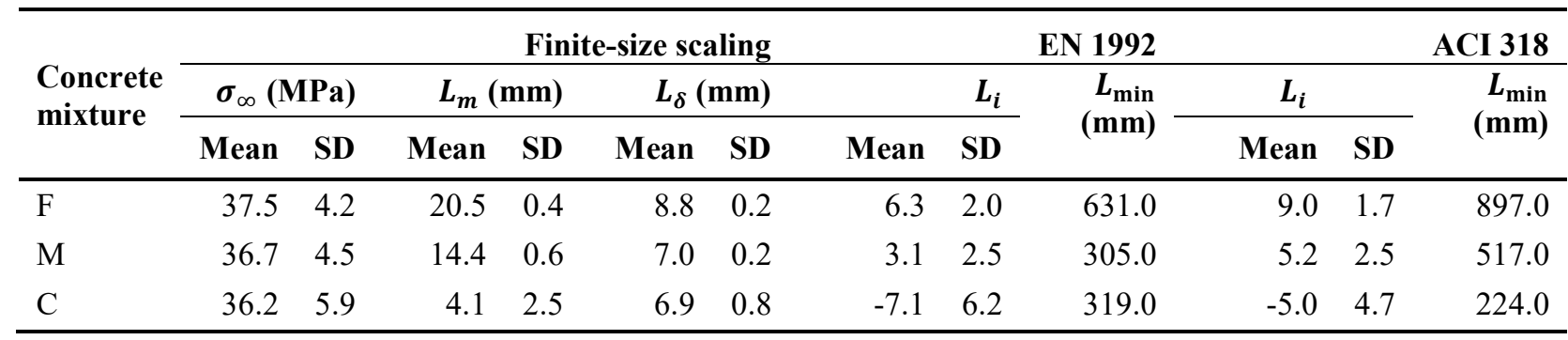

Table 4. Concrete mixture proportions, sample sizes and mean compressive strengths for the three concrete mixtures (M1, M2, M3) of the experiments presented by Dehestani et al. [44], and for the mixture R2 of Muciaccia et al. [13].

\begin{tabular}{|c|c|c|c|c|c|c|c|c|}
\hline \multicolumn{3}{|c|}{ Concrete mix data } & \multirow{2}{*}{$\begin{array}{r}\text { Cylinders } \\
(h / \phi=2) \\
\phi(\mathrm{mm})\end{array}$} & \multirow{2}{*}{$\begin{array}{r}\text { Mean compressive } \\
\text { strength, } \\
\left\langle\sigma_{f}\right\rangle(\mathrm{MPa})\end{array}$} & \multicolumn{2}{|c|}{$\begin{array}{r}\text { Asymptotic strength, } \\
\sigma_{\infty} \text { (MPa) }\end{array}$} & \multicolumn{2}{|c|}{$L_{m}(\mathrm{~mm})$} \\
\hline Mixture code & $\mathbf{W} / \mathbf{C}$ & $d_{\max }(\mathrm{mm})$ & & & Mean & SD & Mean & SD \\
\hline \multirow{4}{*}{$\mathrm{M}^{\mathrm{a}}$} & \multirow{4}{*}{0.35} & \multirow{4}{*}{12.5} & 50 & 51.3 & \multirow{4}{*}{43.7} & \multirow{4}{*}{8.6} & \multirow{4}{*}{9.6} & \multirow{4}{*}{6.4} \\
\hline & & & 75 & 51.0 & & & & \\
\hline & & & 100 & 48.1 & & & & \\
\hline & & & 150 & 45.6 & & & & \\
\hline \multirow{4}{*}{$\mathrm{M} 2^{\mathrm{a}}$} & \multirow{4}{*}{0.39} & \multirow{4}{*}{12.5} & 50 & 41.7 & \multirow{4}{*}{29.7} & \multirow{4}{*}{3.1} & \multirow{4}{*}{19.7} & \multirow{4}{*}{9.7} \\
\hline & & & 75 & 36.9 & & & & \\
\hline & & & 100 & 35.5 & & & & \\
\hline & & & 150 & 33.9 & & & & \\
\hline \multirow{4}{*}{$\mathrm{M}^{\mathrm{a}}$} & \multirow{4}{*}{0.43} & \multirow{4}{*}{12.5} & 50 & 28.4 & \multirow{4}{*}{22.1} & \multirow{4}{*}{1.5} & \multirow{4}{*}{14.6} & \multirow{4}{*}{5.8} \\
\hline & & & 75 & 26.5 & & & & \\
\hline & & & 100 & 25.5 & & & & \\
\hline & & & 150 & 24.0 & & & & \\
\hline \multirow{4}{*}{$\mathrm{R} 2^{\mathrm{b}}$} & \multirow{4}{*}{0.41} & \multirow{4}{*}{20.0} & 100 & 54.4 & \multirow{4}{*}{25.0} & \multirow{4}{*}{13.8} & \multirow{4}{*}{90.5} & \multirow{4}{*}{37.6} \\
\hline & & & 200 & 45.7 & & & & \\
\hline & & & 400 & 37.0 & & & & \\
\hline & & & 800 & 22.8 & & & & \\
\hline
\end{tabular}

a Self-Consolidating Concrete (SCC) mixture;

${ }^{b}$ Normal-weight concrete mixture. 
Table 5. Concrete mixture proportions, sample sizes and mean compressive strengths for the three concrete mixes (A43-0, S47-100, N55-100) of the experiments reported by Sim et al. [50].

\begin{tabular}{|c|c|c|c|c|c|c|c|c|c|}
\hline \multicolumn{4}{|c|}{ Concrete mix data } & \multirow{2}{*}{$\begin{array}{r}\begin{array}{r}\text { Cylinders } \\
(h / \phi=2)\end{array} \\
\phi(\mathrm{mm})\end{array}$} & \multirow[t]{2}{*}{$\begin{array}{r}\text { Mean compressive } \\
\text { strength, }\left\langle\sigma_{f}\right\rangle(\mathrm{MPa})\end{array}$} & \multicolumn{2}{|c|}{$\begin{array}{r}\text { Asymptotic strength, } \\
\sigma_{\infty}(\mathrm{MPa})\end{array}$} & \multicolumn{2}{|c|}{$L_{m}(\mathrm{~mm})$} \\
\hline $\begin{array}{l}\text { Mix } \\
\text { notation }^{a}\end{array}$ & $\mathbf{W} / \mathbf{C}$ & $d_{\max }(\mathrm{mm})$ & $\begin{array}{l}\text { Density, } \\
\rho\left(\mathbf{k g} / \mathbf{c m}^{3}\right)\end{array}$ & & & Mean & SD & Mean & SD \\
\hline & & & & 50 & 50.9 & & & & \\
\hline & & & & 100 & 43.6 & & & & \\
\hline & & & & 150 & 39.4 & & & & \\
\hline \multirow[t]{7}{*}{ A43-0 } & 0.43 & 19 & 1661 & 250 & 33.1 & 27.6 & 4.1 & 46.2 & 23.0 \\
\hline & & & & 300 & 30.2 & & & & \\
\hline & & & & 350 & 30.0 & & & & \\
\hline & & & & 400 & 28.6 & & & & \\
\hline & & & & 50 & 50.7 & & & & \\
\hline & & & & 100 & 43.4 & & & & \\
\hline & & & & 150 & 37.8 & & & & \\
\hline \multirow[t]{7}{*}{ S47-100 } & 0.47 & 5 & 1920 & 250 & 33.0 & 28.6 & 2.7 & 41.3 & 14.1 \\
\hline & & & & 300 & 32.2 & & & & \\
\hline & & & & 350 & 31.4 & & & & \\
\hline & & & & 400 & 30.0 & & & & \\
\hline & & & & 50 & 49.9 & & & & \\
\hline & & & & 100 & 40.5 & & & & \\
\hline & & & & 150 & 35.5 & & & & \\
\hline \multirow[t]{4}{*}{ N55-100 } & 0.55 & 19 & 2314 & 250 & 33.8 & 27.9 & 1,6 & 40.5 & 8.9 \\
\hline & & & & 300 & 30.8 & & & & \\
\hline & & & & 350 & 30.9 & & & & \\
\hline & & & & 400 & 29.8 & & & & \\
\hline
\end{tabular}

${ }^{a}$ In the concrete mix notation, the first part indicates the type of concrete (A: lightweight concrete; S: mortar; N: normal-weight concrete), while the second and third parts give the water-to-cement ratio and replacement sand. For example, A43-0 indicates an alllightweight concrete mix with $W / C=0.43$ and do not use natural sand for casting. 
Table 6. Concrete mixture proportions, specimen sizes and mean compressive strengths for the experiments reported by Blanks and McNamara [52].

\begin{tabular}{|c|c|c|c|c|c|c|c|c|}
\hline \multicolumn{3}{|c|}{ Concrete mix data } & \multirow{2}{*}{$\begin{array}{c}\text { Cylinders } \\
(h / \phi=2)\end{array}$} & \multirow[t]{2}{*}{$\begin{array}{c}\text { Compressive strength, } \\
\left\langle\sigma_{f}\right\rangle(\mathrm{MPa})\end{array}$} & \multicolumn{2}{|c|}{$\begin{array}{r}\text { Asymptotic strength, } \\
\sigma_{\infty}(\mathrm{MPa})\end{array}$} & \multicolumn{2}{|c|}{$L_{m}(\mathbf{m m})$} \\
\hline No. & $\mathbf{W} / \mathbf{C}$ & $d_{\max }(\mathrm{mm})$ & & & Mean & SD & Mean & SD \\
\hline \multirow{6}{*}{ B-8 } & \multirow{6}{*}{0.53} & \multirow{6}{*}{38.10} & 152.4 & 27.92 & \multirow{6}{*}{21.8} & \multirow{6}{*}{1.3} & \multirow{6}{*}{40.1} & \multirow{6}{*}{5.2} \\
\hline & & & 203.2 & 25.72 & & & & \\
\hline & & & 304.8 & 24.75 & & & & \\
\hline & & & 457.2 & 22.89 & & & & \\
\hline & & & 609.6 & 23.44 & & & & \\
\hline & & & 914.4 & 23.30 & & & & \\
\hline \multirow{7}{*}{ B-9 } & \multirow{7}{*}{0.55} & \multirow{7}{*}{19.05} & 50.8 & 27.99 & \multirow{7}{*}{22.5} & \multirow{7}{*}{1.4} & \multirow{7}{*}{14.5} & \multirow{7}{*}{2.1} \\
\hline & & & 76.2 & 27.72 & & & & \\
\hline & & & 152.4 & 25.86 & & & & \\
\hline & & & 203.2 & 23.92 & & & & \\
\hline & & & 304.8 & 23.30 & & & & \\
\hline & & & 457.2 & 23.17 & & & & \\
\hline & & & 609.6 & 22.13 & & & & \\
\hline \multirow{6}{*}{ B-10 } & \multirow{6}{*}{0.54} & \multirow{6}{*}{9.52} & 50.8 & 29.03 & \multirow{6}{*}{22.9} & \multirow{6}{*}{0.8} & \multirow{6}{*}{13.8} & \multirow{6}{*}{1.3} \\
\hline & & & 76.2 & 27.10 & & & & \\
\hline & & & 152.4 & 24.48 & & & & \\
\hline & & & 203.2 & 24.89 & & & & \\
\hline & & & 304.8 & 24.34 & & & & \\
\hline & & & 457.2 & 23.03 & & & & \\
\hline
\end{tabular}


Table 7. Example of application of the proposed procedure for checking the conformity of concrete with the strength requirement for our three concrete mixtures.

\begin{tabular}{llrrr}
\hline Parameter & & F-concrete & M-concrete & C-concrete \\
\hline Compressive strength class C35/45 & $\sigma_{\infty}=f_{c k}=35 \mathrm{MPa}$ & & & \\
\hline Mean compressive strength (MPa) & $\left\langle\sigma_{f}\right\rangle$ & 41.9 & 39.2 & 36.7 \\
\hline Sample size (mm) & $L$ & 160 & 160 & 160 \\
\hline Porosity (\%) & $p_{o}$ & 4.8 & 1.6 & 1.5 \\
\hline Maximum pore diameter $(\mathrm{mm})$ & $d_{p, \max }$ & 6.9 & 6.7 & 5.4 \\
\hline $\begin{array}{l}\text { Minimum required average strength } \\
\text { (MPa) }\end{array}$ & $f_{m r}=\sigma_{\infty}\left[\frac{0.7\left(p_{o} \times d_{p, \max }\right)}{L}+1\right]$ & 40.1 & 36.6 & 36.2 \\
\hline Acceptance condition & $\left\langle\sigma_{f}\right\rangle \geq f_{m r}$ & passed & passed & passed \\
\hline
\end{tabular}

${ }^{I}$ The porosity $p_{o}$ expressed in $\%$

Table 8. Example of application of the proposed procedure for checking the conformity of concrete with the strength requirement for three assumed cases of C-concrete.

\begin{tabular}{llrrr}
\hline Parameter & & Case 1 & Case 2 & Case 3 \\
\hline Compressive strength class C35/45 & $\sigma_{\infty}=f_{c k}=35 \mathrm{MPa}$ & & & \\
\hline Mean compressive strength (MPa) & $\left\langle\sigma_{f}\right\rangle$ & 36.7 & 36.7 & $\mathbf{3 5 . 7}$ \\
\hline Sample size (mm) & $L$ & 160 & 160 & 160 \\
\hline Porosity (\%) & $p_{o}$ & 1.5 & $\mathbf{3 . 5}$ & 1.5 \\
\hline Maximum pore diameter $(\mathrm{mm})$ & $d_{p, \max }$ & 5.4 & 5.4 & 5.4 \\
\hline $\begin{array}{l}\text { Minimum required average strength } \\
\text { (MPa) }\end{array}$ & $f_{m r}=\sigma_{\infty}\left[\frac{0.7\left(p_{o} \times d_{p, \max }\right)}{L}+1\right]$ & 36.2 & 37.9 & 36.2 \\
\hline Acceptance condition & $\left\langle\sigma_{f}\right\rangle \geq f_{m r}$ & passed & failed & failed \\
\hline
\end{tabular}

${ }^{I}$ The porosity $p_{o}$ expressed in $\%$. 
Table A.1. Pore structure parameters, averaged over all sections and sample sizes, for the 3 different concrete mixtures.

\begin{tabular}{lrrrrrr}
\hline \multirow{2}{*}{$\begin{array}{l}\text { Concrete } \\
\text { group }\end{array}$} & $\begin{array}{r}\text { Mean pore diameter, } \\
\left\langle\boldsymbol{d}_{\boldsymbol{p}}\right\rangle(\mathbf{m m})\end{array}$ & \multicolumn{2}{c}{$\begin{array}{r}\text { Maximum pore diameter, } \\
\boldsymbol{d}_{\boldsymbol{p}, \mathbf{m a x}}(\mathbf{m m})\end{array}$} & \multicolumn{2}{c}{ Porosity, $\boldsymbol{p}_{\boldsymbol{o}}(\boldsymbol{\%})$} \\
\cline { 2 - 8 } & Mean & SD & Mean & SD & Mean & SD \\
\hline $\mathrm{F}$ & 0.33 & 0.24 & 6.9 & 1.8 & 4.8 & 1.2 \\
$\mathrm{M}$ & 0.31 & 0.21 & 6.7 & 1.2 & 1.6 & 0.4 \\
$\mathrm{C}$ & 0.28 & 0.20 & 5.4 & 1.3 & 1.5 & 0.3 \\
\hline
\end{tabular}




\section{Figure captions}

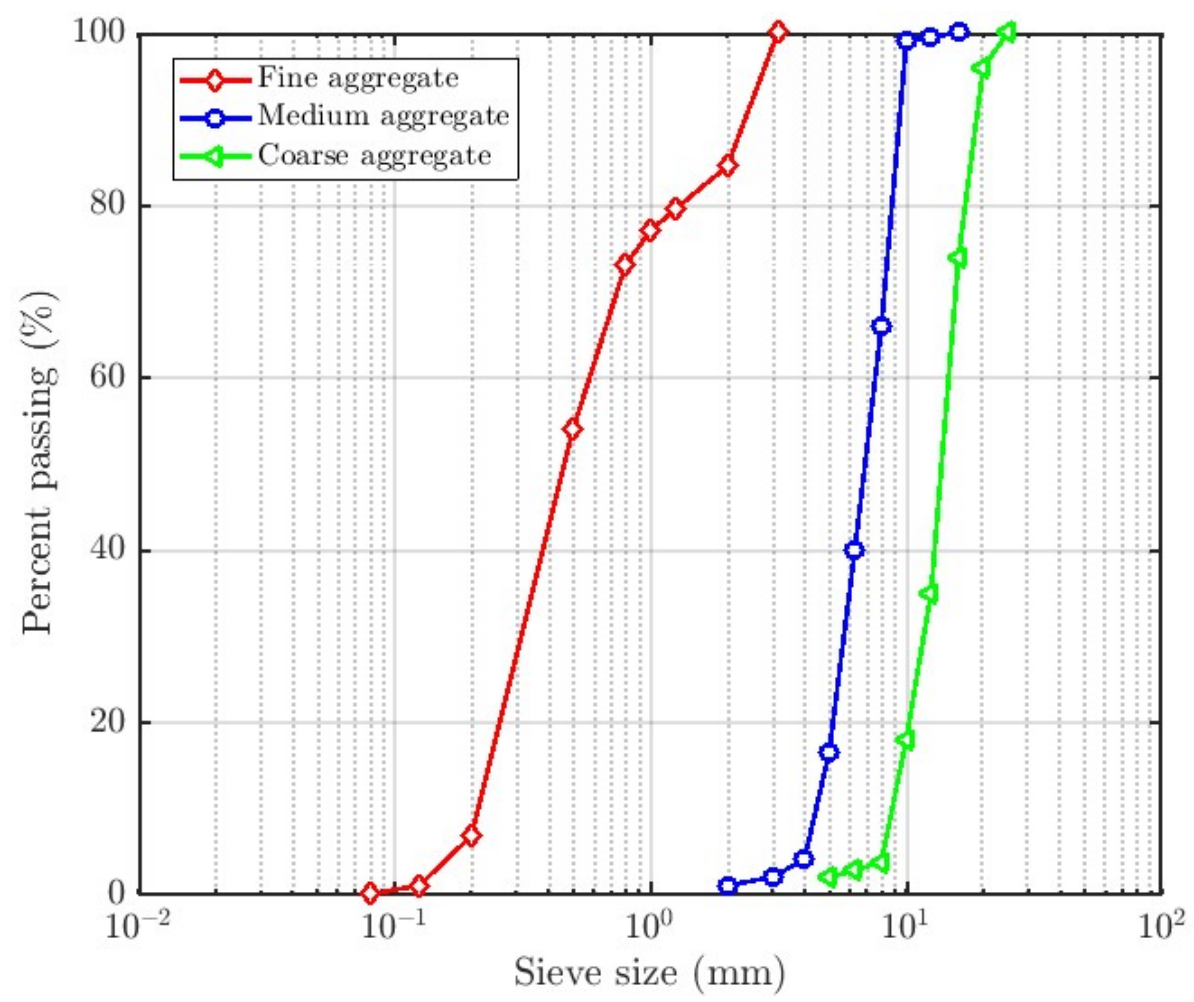

Fig. 1. Grading curves of aggregates for three concrete mixtures 


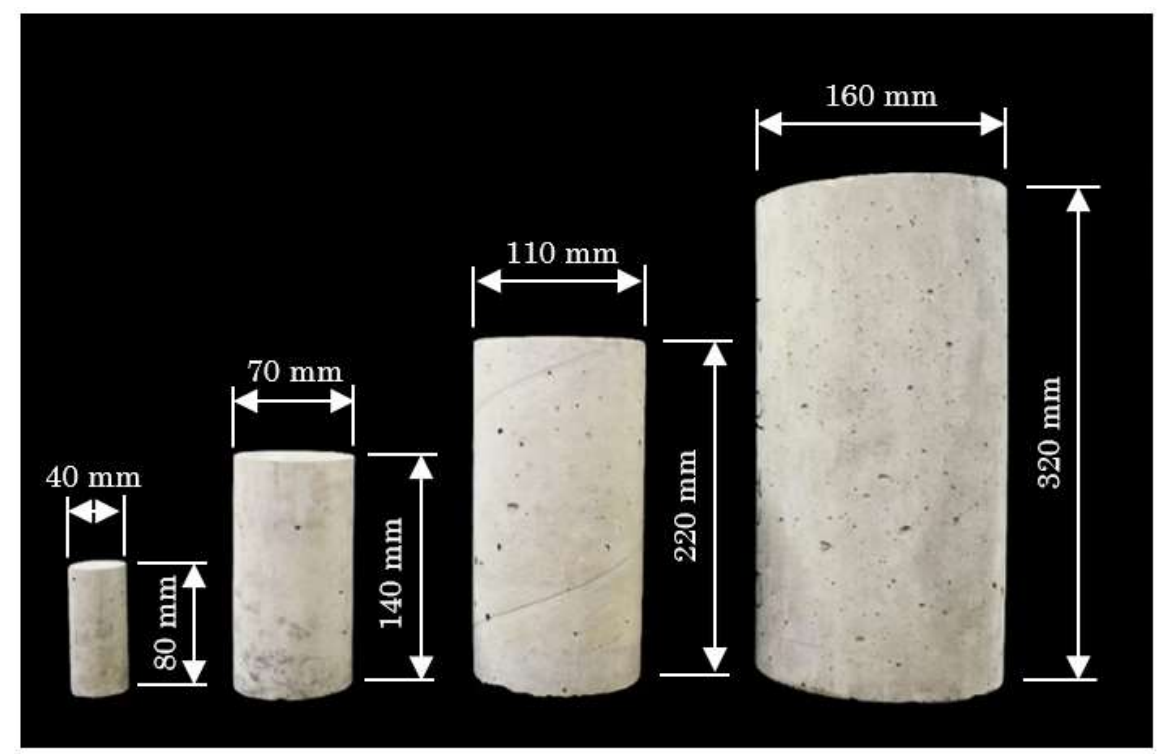

(a)

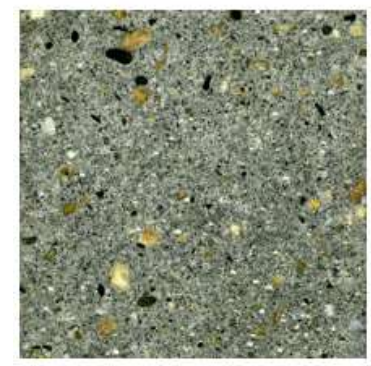

F-Concrete

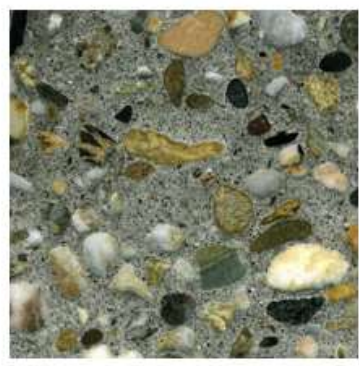

M-Concrete (b)

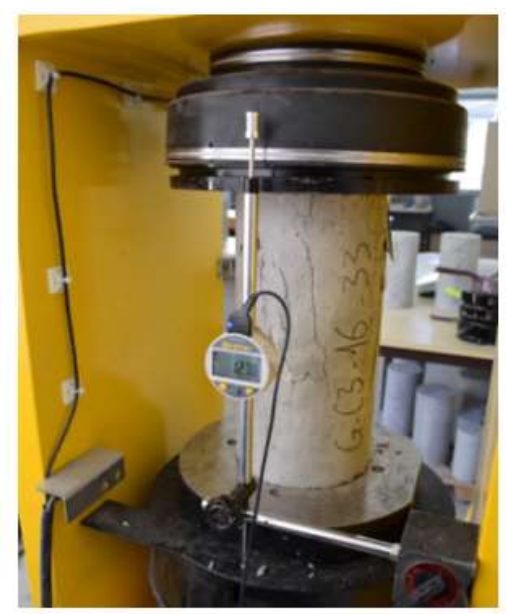

(c)

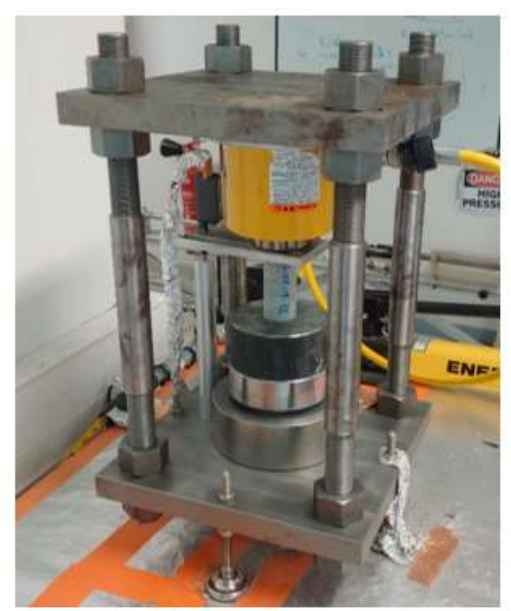

(d)

Fig. 2. Concrete specimens and testing setup: (a) Geometries of the four different sizes of concrete specimens; (b) Cross sections of the three different concrete mixtures; (c) Uniaxial compression testing setup (Machine A); (d) Uniaxial compression testing setup (Machine B). 

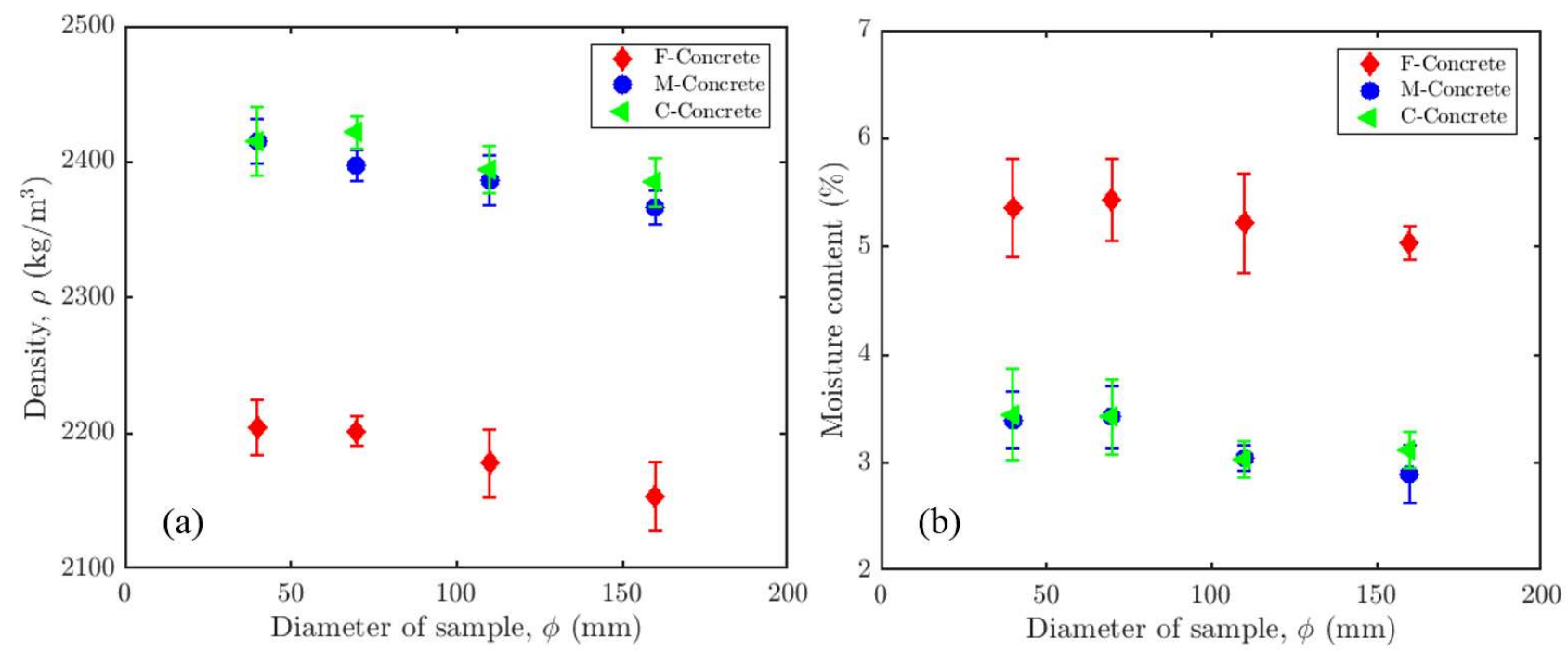

Fig. 3. Properties of hardened concrete samples as a function of the sample diameter: (a) Apparent density; (b) Moisture content 

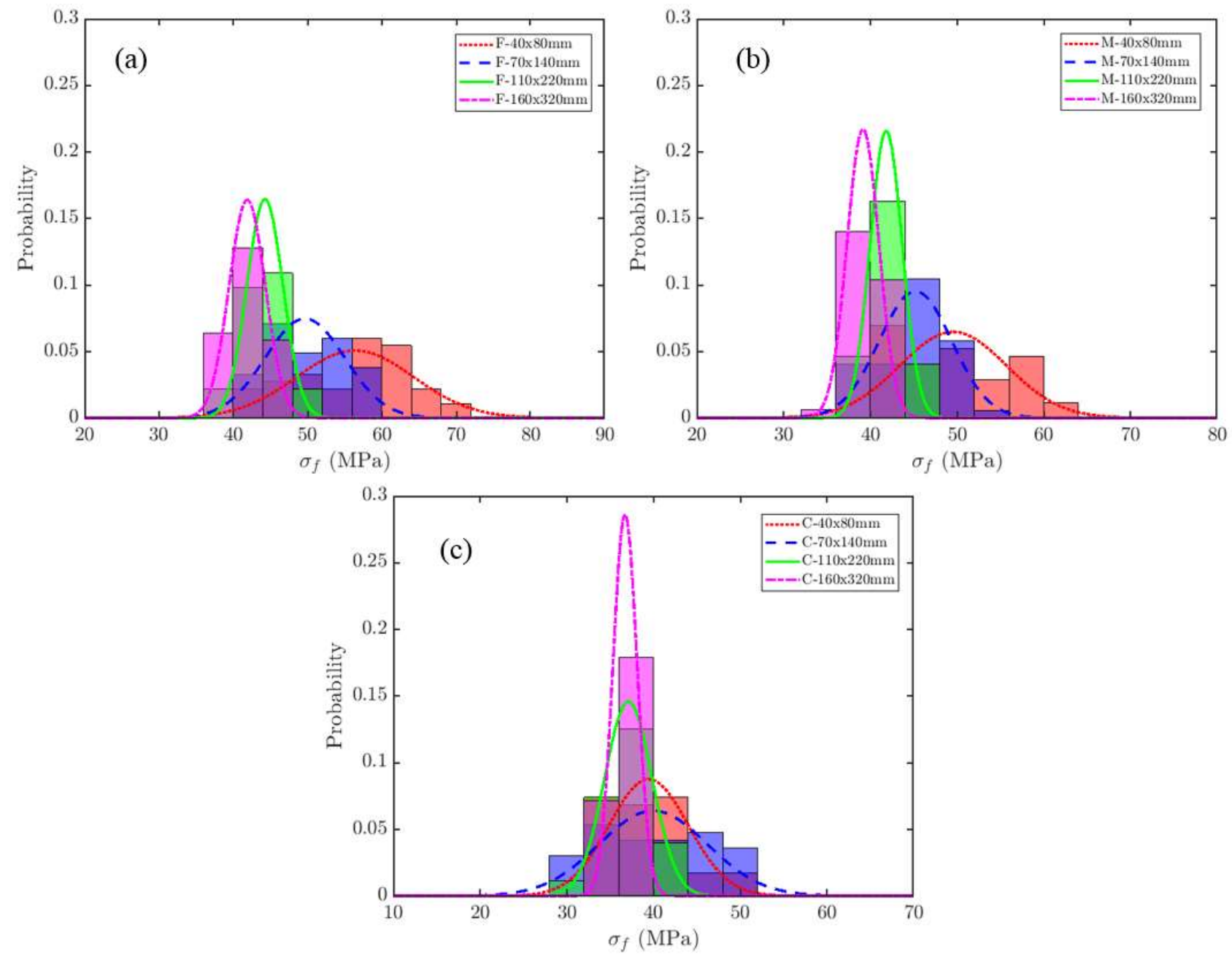

Fig. 4. Histograms and normal distribution fits of the compressive strength of concrete samples: (a) Fconcrete; (b) M-concrete and (c) C-concrete. 

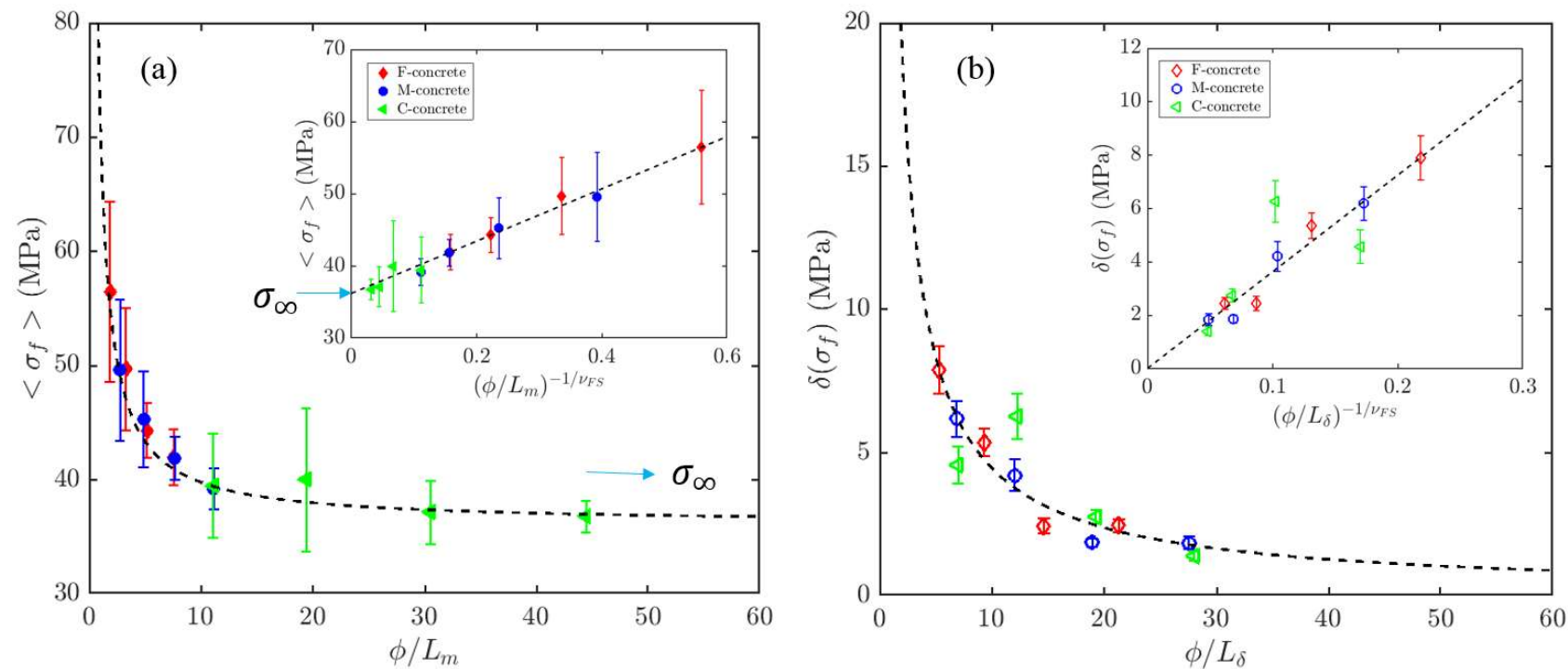

Fig. 5. Finite-size effect on the uniaxial compressive strength of concrete: (a) for the mean strength, $\left\langle\sigma_{f}\right\rangle$ and (b) for the standard deviation of strength, $\delta\left(\sigma_{f}\right)$. Main graphs show the relationship between $\left\langle\sigma_{f}\right\rangle$ and $\delta\left(\sigma_{f}\right)$ with the ratio of sample size $(\phi)$ to the length scales $L_{m}$ and $L_{\delta}$, respectively. Black dashed-lines are the fits by Eq. (3) for the mean strength (a), and Eq. (4) for the standard deviation of strength (b). Insets show the same data and fits on $\left[\left\langle\sigma_{f}\right\rangle v s .\left(\phi / L_{m}\right)^{-1 / v_{F S}}\right]$ and $\left[\delta\left(\sigma_{f}\right) v s .\left(\phi / L_{\delta}\right)^{-1 / v_{F S}}\right]$ plots where the fits by Eq. (3) and Eq. (4) are the straight lines. 

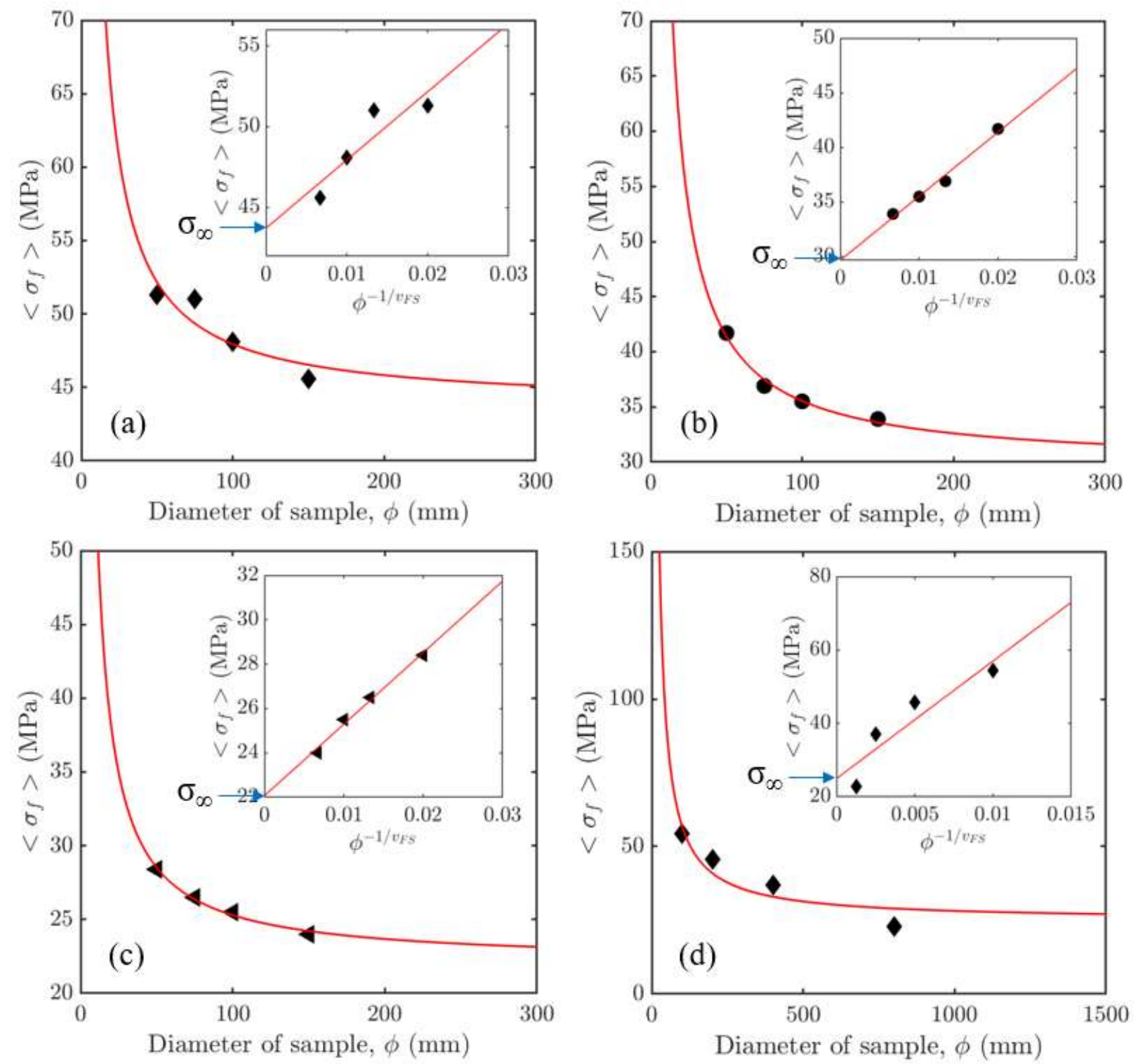

Fig. 6. Finite-size effect on the uniaxial compressive strength (experimental data): for three selfconsolidating concrete (SSC) mixtures (a) M1, (b) M2, and (c) M3 in ref. [44]; and (d) for normal-weight concrete mixture (R2) in ref. [13]. Main graphs show the relationship between $\left\langle\sigma_{f}\right\rangle$ and the sample diameter $(\phi)$. Black symbols are the published experimental data. Red curves are the fits by using Eq. (3) for the mean strength with $v_{F S}=1$. Insets show the same data and fits on $\left[\left\langle\sigma_{f}\right\rangle v s .(\phi)^{-1 / v_{F S}}\right]$ plots where the fits by Eq. (3) are the straight lines. The best-fit asymptotic strength $\sigma_{\infty}$ and the associated length scale $L_{m}$ for each concrete group are listed in Table 4. 

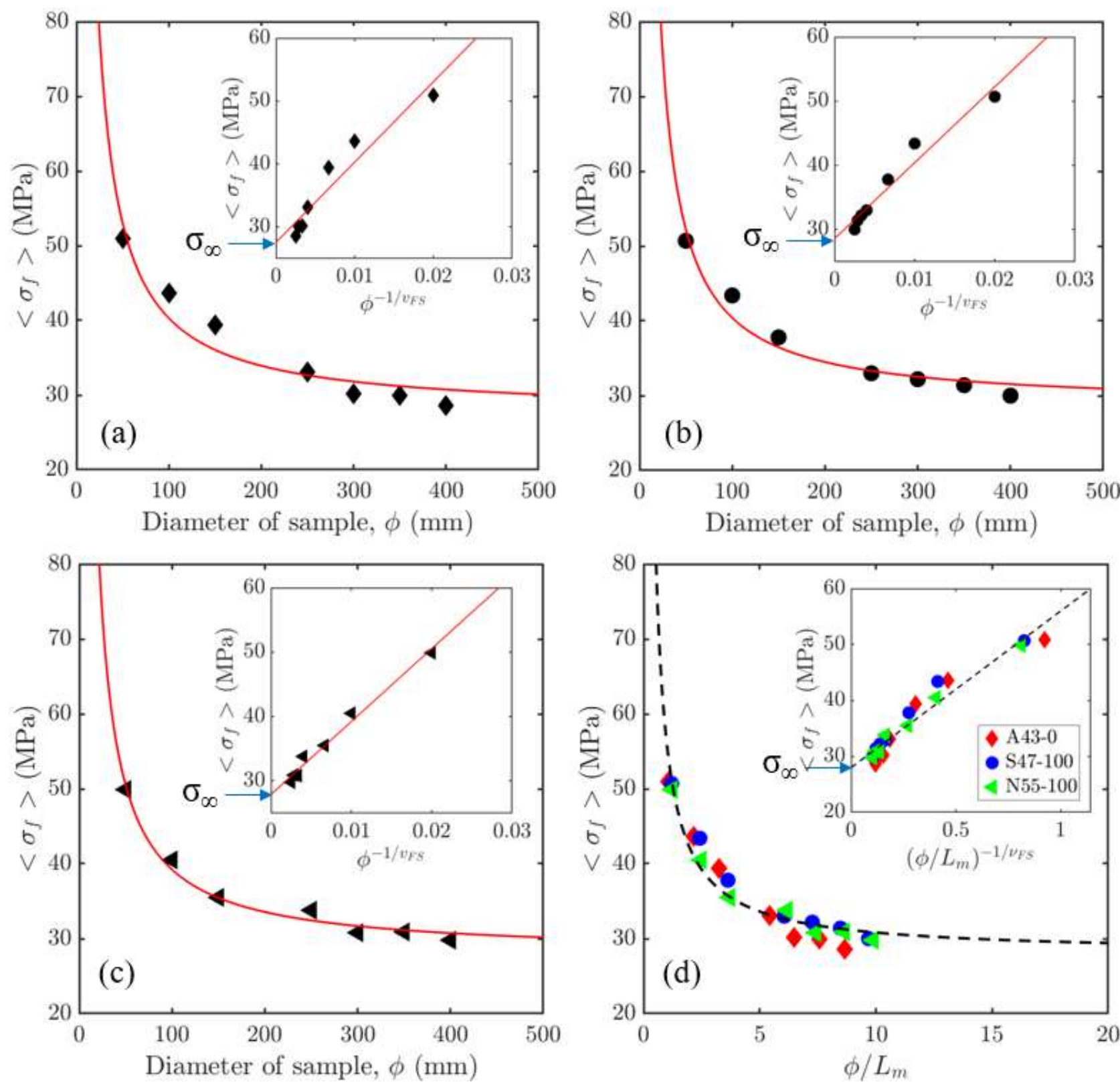

Fig. 7. Finite-size effect on the mean compressive strength for three different concrete mixtures of ref. [50]: (a) A43-0; (b) S47-100; (c) N55-100. Main graphs show the mean compressive strength, $\left\langle\sigma_{f}\right\rangle$ as a function of sample diameter $(\phi)$. Black symbols are the experimental data reported by [50]. Red curves are the fitting by Eq. (3). Insets show the same data and fits in a $\left[\left\langle\sigma_{f}\right\rangle v s . \phi^{-1 / v_{F S}}\right]$ graph. In this smaller graph, the fitting by Eq. (3) becomes a straight line and the asymptotic strength $\sigma_{\infty}$ is determined. In (d), the collapse of all data for all concrete mix with a common asymptotic strength $\left(\sigma_{\infty}=28.0 \pm 0.6\right)$ is shown. 

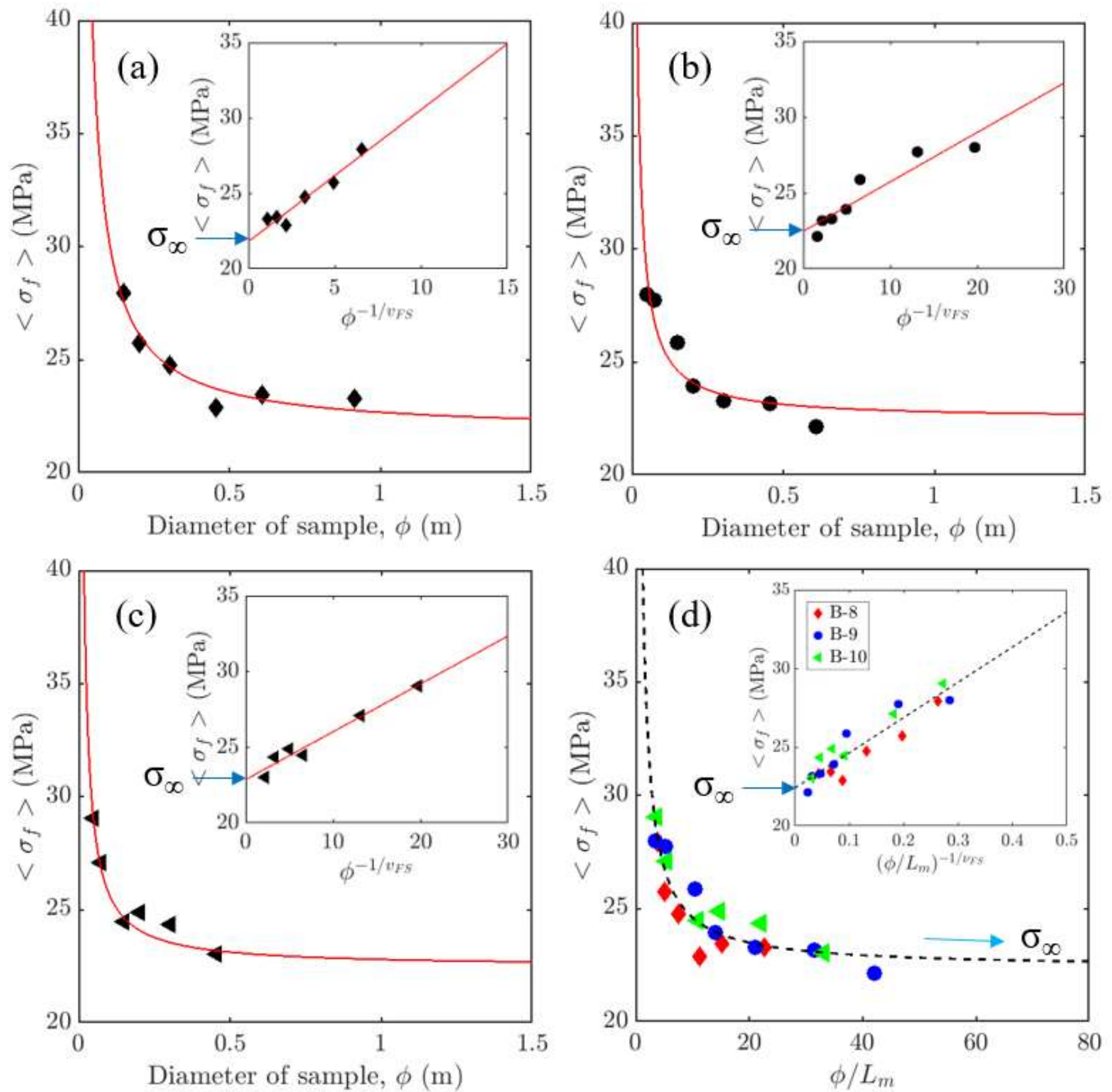

Fig. 8. Finite-size effect on the mean compressive strength for: (a) B-8; (b) B-9; (c) B-10 concrete mixtures of ref. [52]. Main graphs show the mean compressive strength, $\left\langle\sigma_{f}\right\rangle$ as a function of specimen size. Black symbols are the experimental data reported by [52]. Red curves are the fitting by Eq. (3). Insets show the same data and fits in a $\left[\left\langle\sigma_{f}\right\rangle v s . \phi^{-1 / v_{F S}}\right]$ graph. In this smaller graph, the fitting by Eq. (3) becomes a straight line and the asymptotic strength $\sigma_{\infty}$ is determined. In (d), the collapse of all data for all concrete mix with a common asymptotic strength $\left(\sigma_{\infty}=22.4 \pm 0.3\right)$ is shown. 


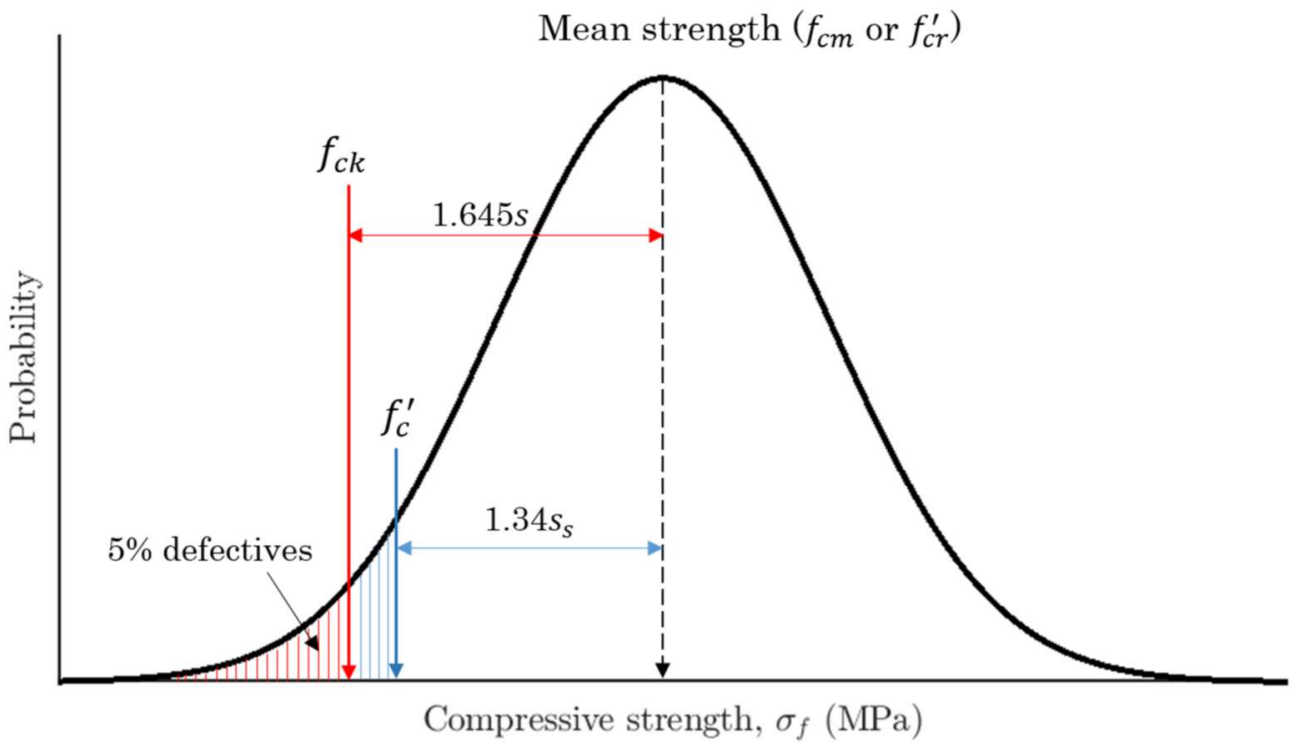

Fig. 9. Normal distribution curve for the compressive strength of concrete samples (modified from [80]). 

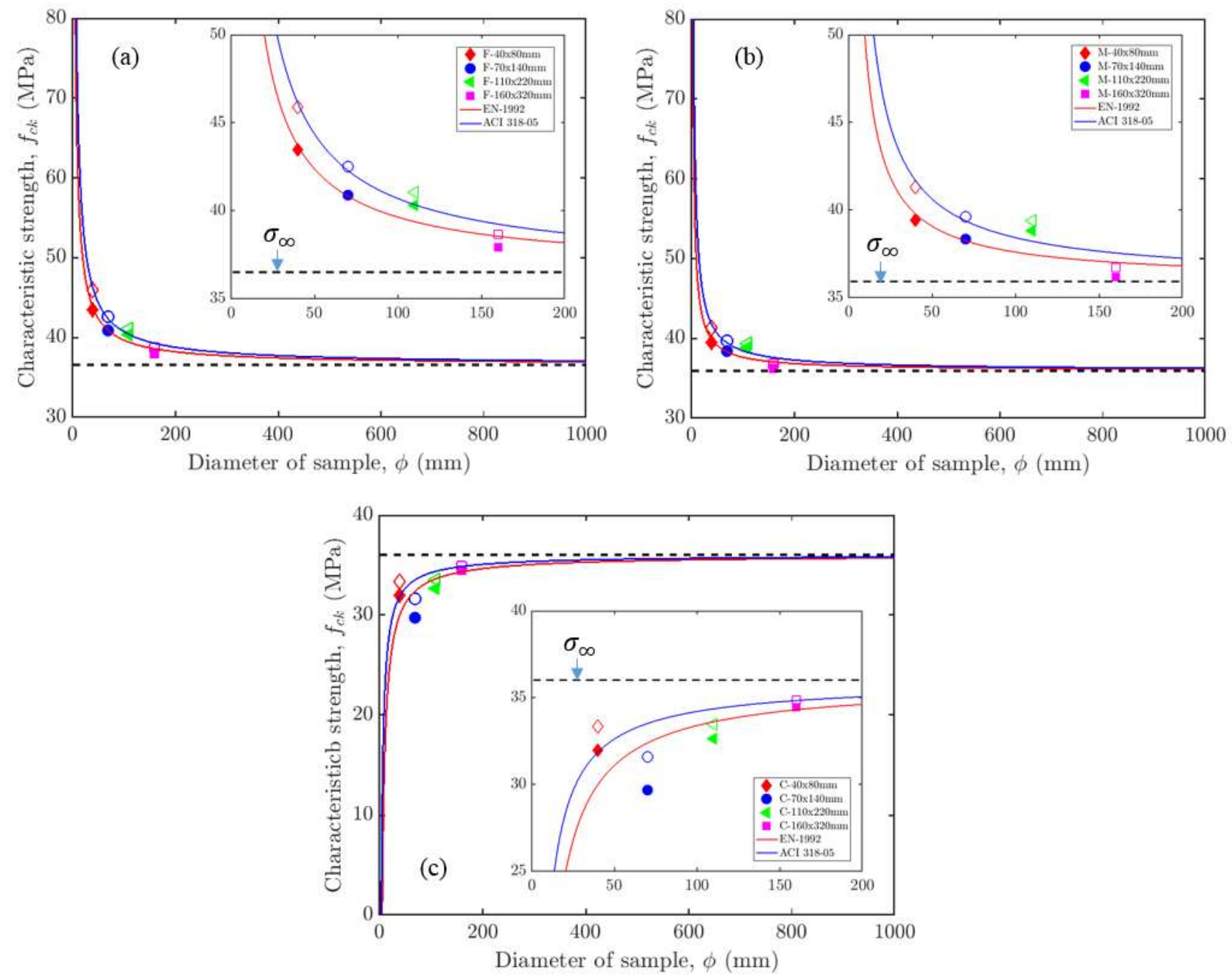

Fig. 10. Comparison between the asymptotic strength, $\sigma_{\infty}$ (dashed black line), determined form the finitesize scaling of the mean strength (Eq. (3)), and the estimated values of the characteristic strength, $f_{c k}$, following the Eurocode 2 (filled symbols) and ACI-318 (open symbols): (a) F-concrete; (b) M-concrete and (c) C-concretes. The red and blue curves are the fits by Eq. (5) for the $f_{c k}$ values of all concrete mixtures according to the EN 1992 and ACI 318 design codes, respectively. 


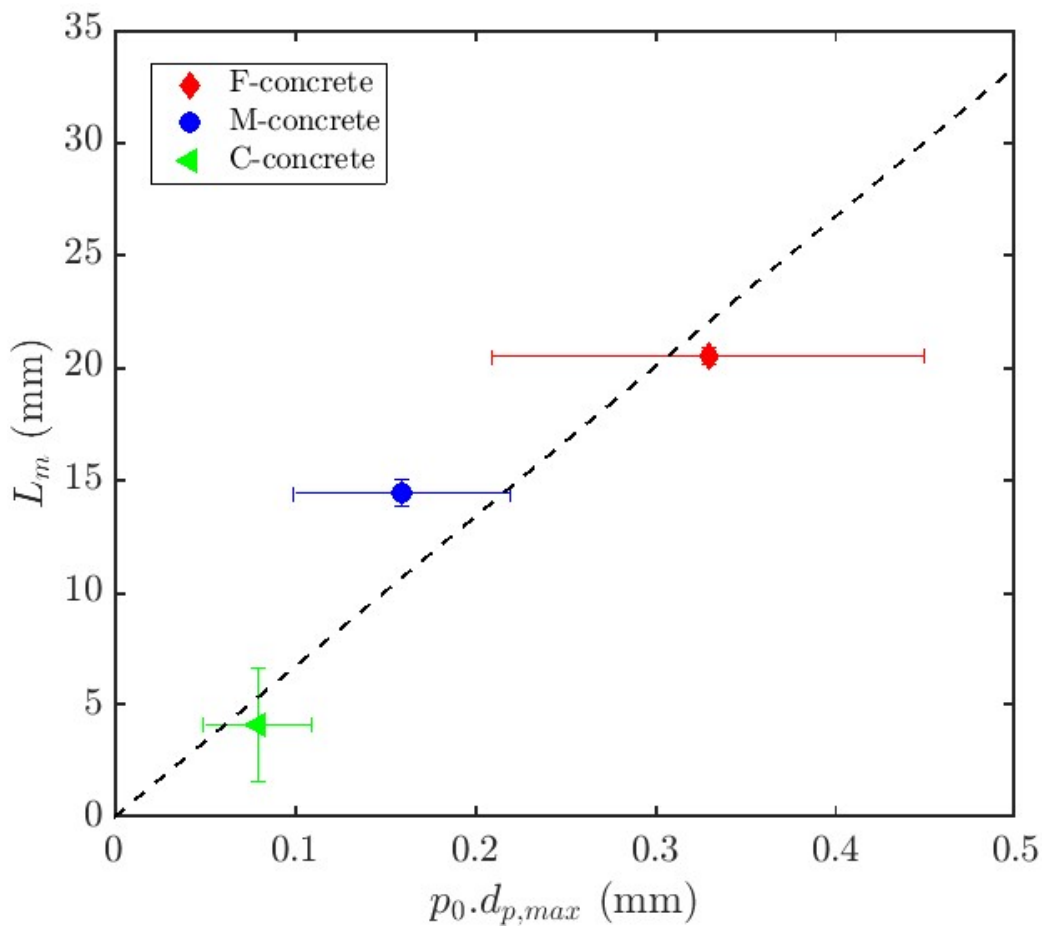

Fig. 11. Relationship between the length scale $\left(L_{m}\right)$ and the product $\left(p_{o} \times d_{p, \max }\right)$. 


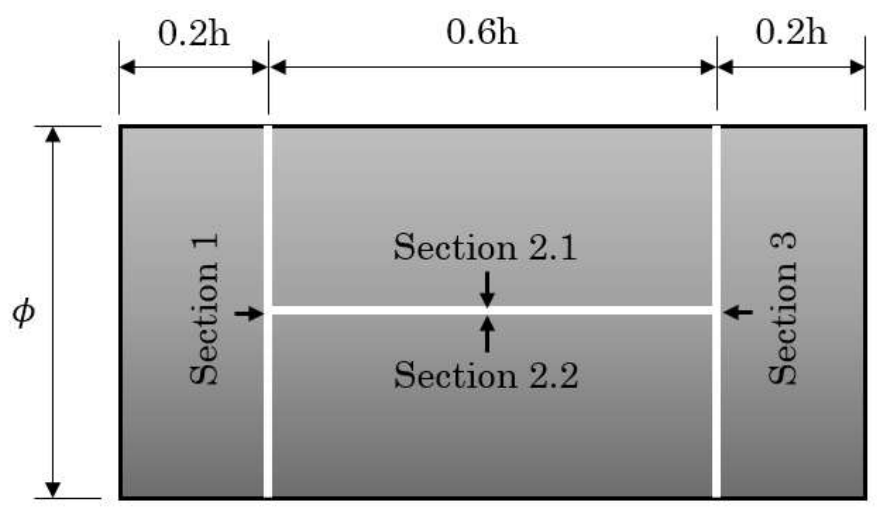

(a)

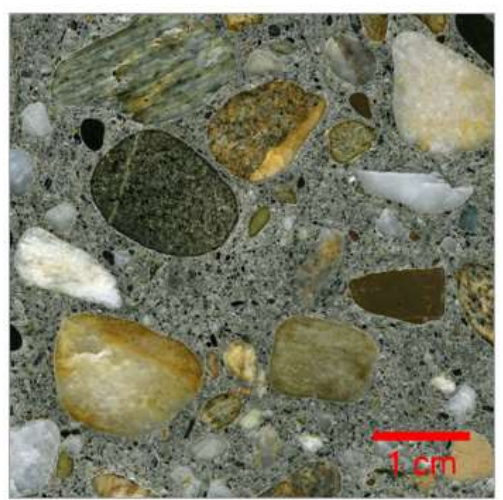

(b)

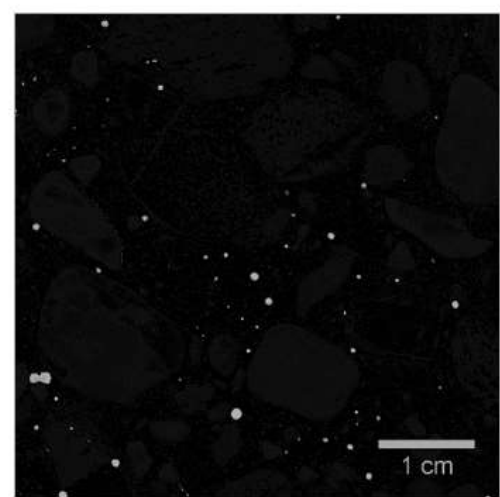

(c)

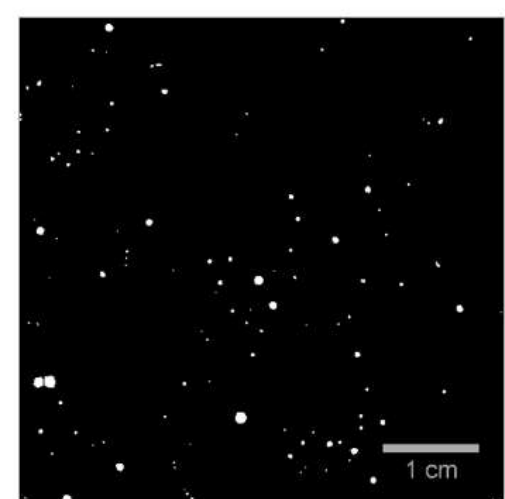

(d)

Fig. A.1. Image analysis procedure of the pore structure: (a) cutting sections of the concrete sample; (b) concrete sample surface after grinding and polishing; (c) scanned image of pores after the contrast enhancement operation; (d) binary image of pores obtained after thresholding. (adapted from [15]). 

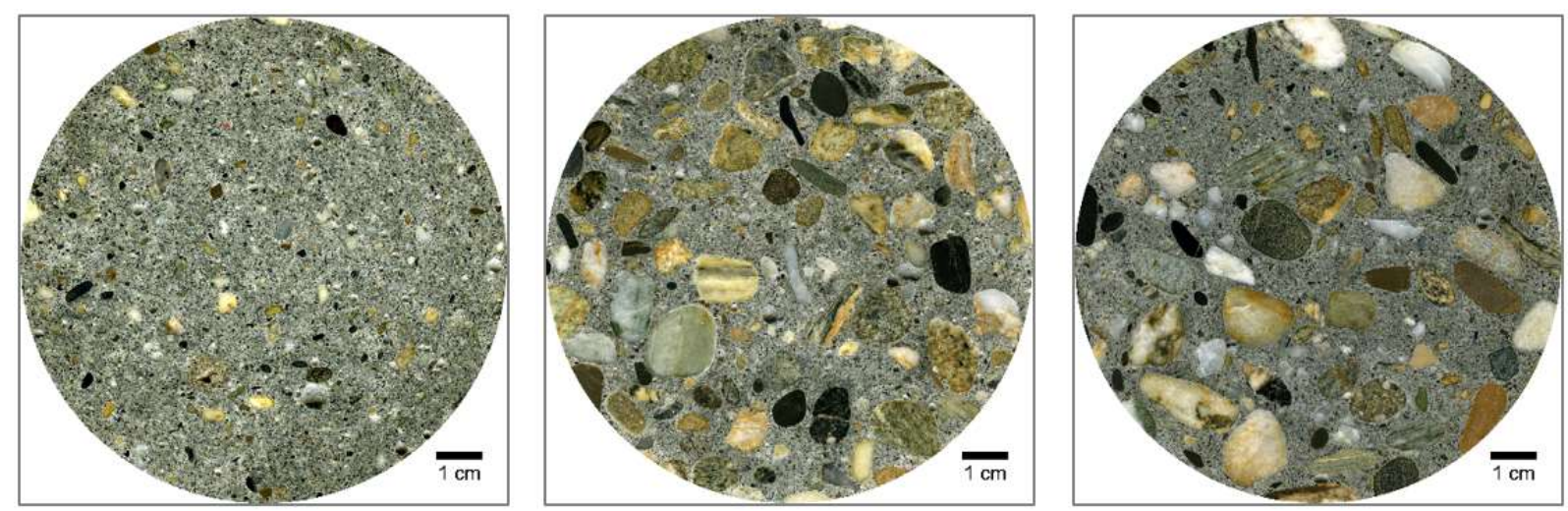

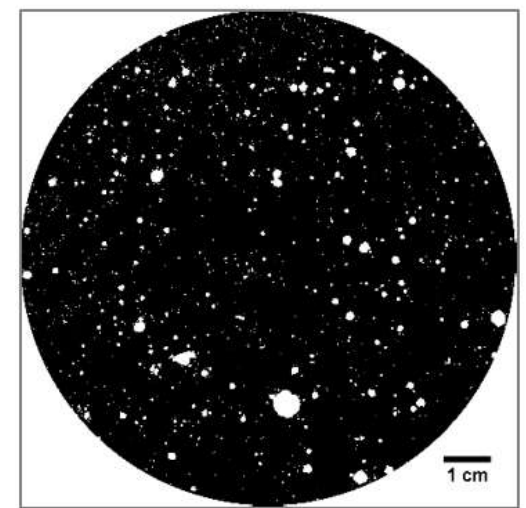

(a)

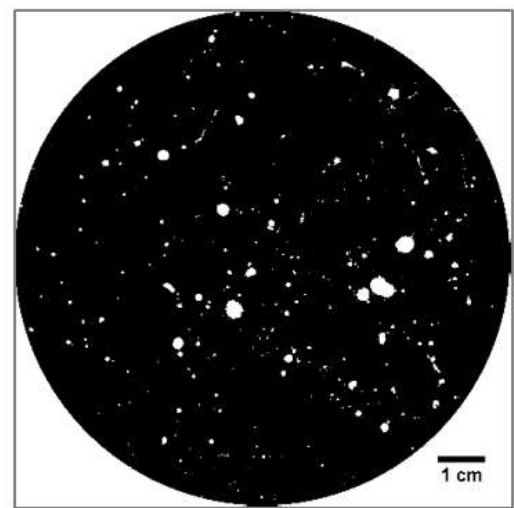

(b)

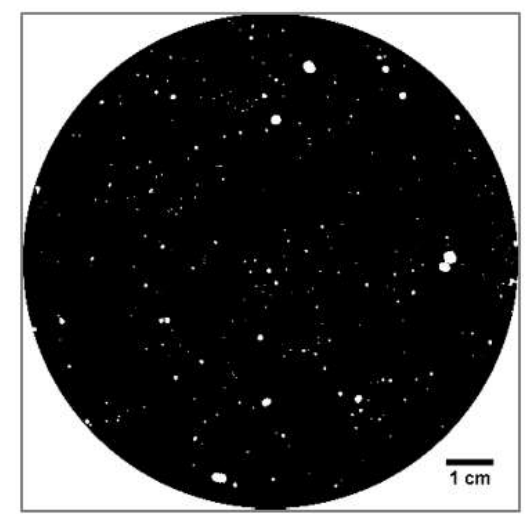

(c)

Fig. A.2. Comparison of the pore structure for three different concrete mixtures; (a) F-110x220mm; (b) M$110 \times 220 \mathrm{~mm}$; (c) C-110x220mm. Top figures are the original scanned images and bottom figures are the corresponding binary images of pores. (from [15]). 

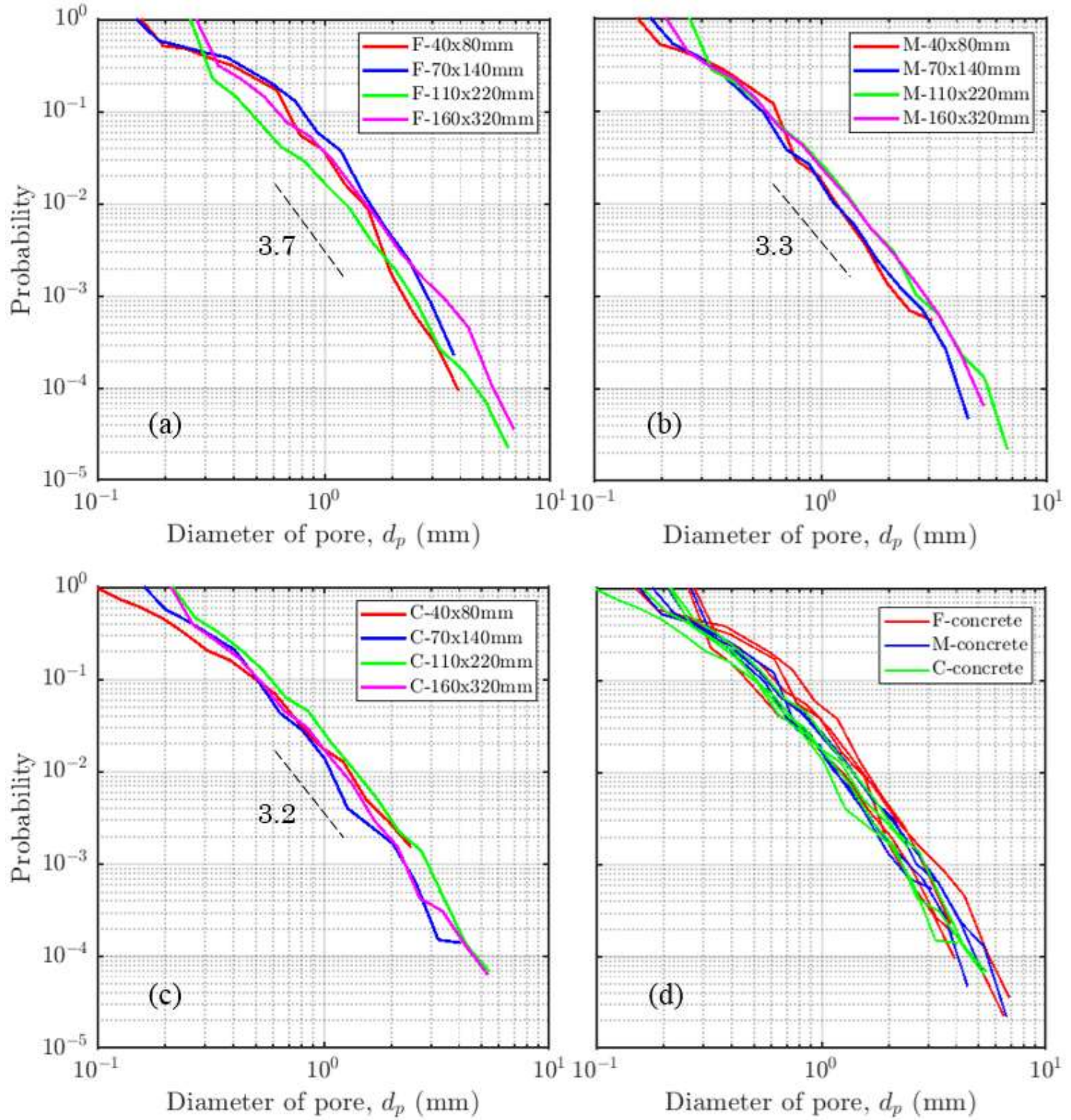

Fig. A.3. Size distribution of pores per unit volume for different concrete samples. (a) F-concrete; (b) Mconcrete; (c) C-concrete and (d) All concrete samples. 